\title{
LA DEBILIDAD INSTITUCIONAL EN EL PERÚ: ¿LA FALTA DE COMPETENCIA POLÍTICA LIMITA EL FORTALECIMIENTO INSTITUCIONAL?
}

\section{INSTITUTIONAL WEAKNESS IN PERU: DOES THE LACK OF POLITICAL COMPETITION LIMITS THE CAPACITY BUILDING?}

\section{Vladirmir Rodríguez Cairo *}

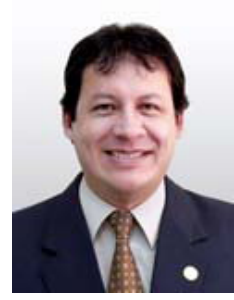

Docente Asociado de la Facultad de Ciencias Contables - UNMSM

[Recepción: Setiembre de 2011/ Conformidad: Noviembre 2011]

\section{RESUMEN}

En la actualidad hay un consenso en reconocer la importancia de las instituciones -reglas de juego de la sociedad: formales e informales- para explicar tanto el éxito como el fracaso de los países en la búsqueda de su desarrollo. En esa perspectiva, el Perú no ha alcanzado el tan ansiado desarrollo económico debido a que existe un marco institucional débil y no se protegen de manera efectiva los derechos individuales.

El marco institucional ha conducido a lo largo de nuestra historia, al establecimiento de formas de gobierno, populistas y autoritarias. Nuestro sistema judicial no funciona adecuadamente: los procesos judiciales son ineficientes (altos costos y lentitud en los procesos), hay influencia política, las decisiones judiciales son inciertas, existe corrupción generalizada, y el acceso a la justicia es desigual. Como resultado de estas características, el sistema judicial promueve la inseguridad jurídica. Sumado a lo anterior, no contamos con un sistema de partidos políticos sólidos.

La debilidad institucional afecta nuestro desempeño económico debido a que la inversión de las empresas se ve afectada y por otro lado, los derechos de propiedad son inciertos o inconstantes, por ello se requiere fortalecer nuestro marco institucional, especialmente de la existencia de instituciones que aseguren los derechos de propiedad y mecanismos legales que los protejan. No se trata simplemente de dar leyes, es necesario velar por el cumplimiento de las mismas.

A continuación se presenta los antecedentes del institucionalismo, el marco teórico y conceptual de las instituciones y organizaciones, así como un breve análisis de la debilidad institucional y el fortalecimiento institucional, concluyendo con las ideas más importantes.

Palabras Clave: Competencia política, fortalecimiento institucional, estructura política, estructura organizacional.

\begin{abstract}
At present there is a consensus in recognizing the importance of institutions, rules of society: formal and informal-to explain both success and failure of countries seeking development. In this perspective, Peru has not reached the longed-economic development because there is a weak institutional framework and does not effectively protect individual rights. The institutional framework has led throughout our history, the establishment of forms of government, populist and authoritarian. Our judicial system is not working properly: the judicial processes are inefficient (high cost and slow processes), there is political influence, court decisions are uncertain, there is widespread corruption, and access to justice is uneven. As a result of these characteristics, the legal system promotes legal uncertainty. In addition to the above, do not have a strong political party system. The institutional weakness affects our economic performance because business investment is affected and on the other hand, property rights are unclear or inconsistent, so we need to strengthen our institutional framework, especially the existence of institutions that ensure property rights and legal mechanisms to protect them. It is not simply to make laws, it is necessary to ensure compliance with them. Below is the history of institutionalism, the theoretical and conceptual framework of institutions and organizations as well as a brief analysis of the institutional weaknesses and capacity building, concluding with the most important ideas.
\end{abstract}

Keywords: competition policy, institutional strengthening, political, organizational structure.

\footnotetext{
* Doctor en Derecho y Ciencia Política - UNMSM, Magíster en Economía - UNMSM. Director del Centro de Extensión Universitaria y Proyección Social (CEUPS) - UNMSM, Docente Investigador de la Facultad de Ciencias Contables -UNMSM, Docente Asociado de la Facultad de Ciencias Contables-UNMSM.
} 


\section{INTRODUCCIÓN}

Según Ayala (2004:25), para muchos, el institucionalismo se identifica con la economía política clásica, porque asume el estudio de las relaciones entre los aspectos prácticos de la acción política y la teoría pura de la economía.

A través de la historia, se hicieron muchos intentos por incorporar temas relacionados con las instituciones y el cambio institucional dentro de la disciplina. Los ejemplos más obvios son el institucionalismo americano (institucionalismo tradicional) y la nueva economía institucional (neoinstitucionalismo). Sin embargo, el análisis institucional puede encontrarse en obras de economistas clásicos y neoclásicos; en miembros de las escuelas históricas alemana, inglesa, americana, austriaca, inclusive en la Escuela de Chicago ${ }^{1}$ , por el importante énfasis que ponen a los derechos de propiedad, los costos de transacción, fallas de mercado ${ }^{2}$ y economía de la información.

En esa perspectiva, los antecedentes del institucionalismo son remotos, su origen se encuentra en los economistas clásicos, el historicismo alemán, la escuela austríaca, el marxismo. En el siguiente diagrama ${ }^{3}$ , se presentan las principales relaciones e influencias de las escuelas del pensamiento económico en su evolución.

Diagrama N.o 01 : Evolución del Institucionalismo Económico

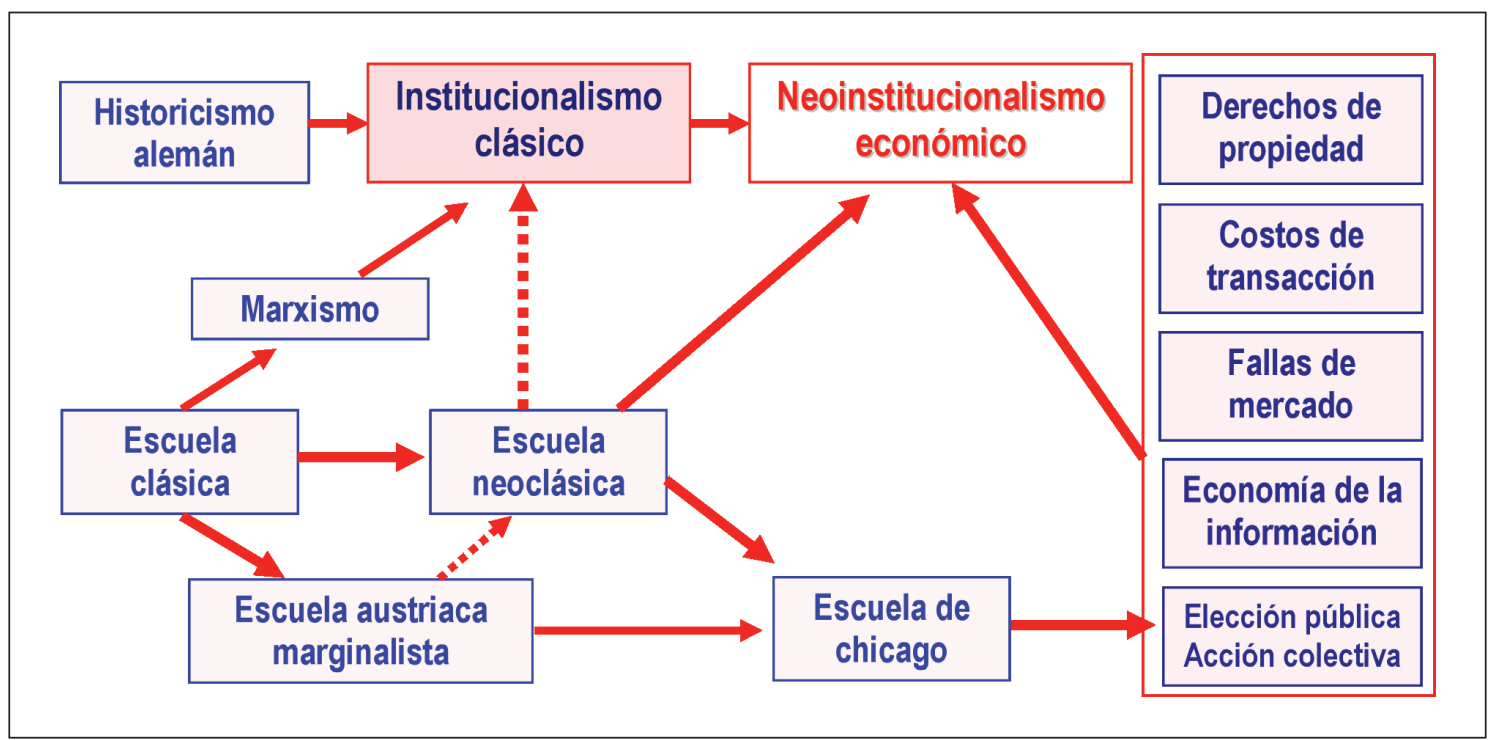

1 Grupo de economistas (de los cuales los más destacados han sido Henry Simons, Milton Friedman, George Stigler, Gary Becker y Arnold Harberger); sostienen que el libre mercado y la competencia contribuirán a que el funcionamiento de la economía sea más eficiente; el mercado competitivo es la mejor forma de organización de la actividad económica. Postulan una intervención mínima del Estado en la economía, además, el sistema monetario tiene una importancia primordial en un país.

2 Las fallas del mercado se refieren a situaciones concretas en las que están presentes todas o algunas de las causas de ineficiencia: 1) Cuando los agentes no tienen suficiente control sobre los productos como para efectuar intercambios ventajosos; 2) No se dispone de suficiente o adecuada información (información imperfecta o asimétrica); 3 ) Cuando las partes individuales en un intercambio no pueden ponerse de acuerdo en cómo distribuirse las ganancias de su intercambio mutuamente provechoso; 4) Existencia de bienes públicos que distorsionan el mercado; 5) Presencia de externalidades.

3 Diagrama reelaborado por José Ayala Espino a partir de J.W. Samuels, Institutional Economics; Edward Elgar, Londres 1988. 
Para Holmes (1994), los economistas clásicos fueron los pioneros en introducir el análisis de las instituciones para explicar el intercambio económico, sin embargo, no desarrollaron una teoría formal de las instituciones. Los clásicos ${ }^{4}$ estaban conscientes de que la conducta humana no depende, la mayoría de las veces, del cálculo económico, sino de los hábitos y aún de las emociones, y que muchas veces las metas humanas no son materiales. Hoy se comienza a admitir que la conducta racional y calculadora es una simplificación burda de las ideas liberales.

Los pensadores liberales, que defienden la ideas individualistas, admiten la conducta egoísta, pero solo como un punto de partida y no de llegada $^{5 .}$ En esa orientación, Bastiat ${ }^{6}$ sostiene que el libre mercado era inherentemente una fuente de "armonía económica" entre los individuos, siempre que el gobierno se limitara a proteger las vidas, las libertades y la propiedad de los ciudadanos. No fue ni el primer ni el último economista en recomendar una sociedad libre. Otros, desde A. Smith hasta F. A. Hayek , han hecho eso.
En fin, los clásicos aceptaron en mayor medida que las instituciones, las reglas, los contratos y en general, las regulaciones del gobierno eran indispensables para entender el funcionamiento de los mercados. Sin embargo, la importancia que los clásicos le habían conferido al papel de las instituciones se fue diluyendo en el pensamiento económico, hasta casi desaparecer.

En efecto los neoclásicos a finales del siglo XIX e inicios del siglo XX se preocuparon poco por el papel de las instituciones. Las ideas de los neoclásicos ${ }^{8}$ se convirtieron en la dominante en Europa Occidental y América del Norte. El intercambio y la conducta económica fueron estudiados como procesos que ocurrían al margen de las instituciones y sólo determinados por el mercado y la conducta de los individuos.

A pesar de la hegemonía del pensamiento de los neoclásicos, algunos economistas como Max Weber (1864-1920) ${ }^{9}$ advirtió la necesidad de analizar simultáneamente las relaciones interinfluyentes entre la economía, las instituciones y los valores.

4 Los clásicos fueron partidarios del librecambio; propugnaron la más absoluta libertad: libre competencia. Entre sus representantes: Adam Smith, David Ricardo, John Stuart Mill y Malthus.

5 Los liberales sostienen un conjunto de ideas de orden político o social que favorecen la máxima libertad en lo económico, con la libre contratación de trabajo, la libertad de comercio de bienes y la libre circulación de capitales; todo ello sin intervenciones del Estado (El Estado sólo debe dedicarse a actividades indispensables como: defensa, moneda, hacienda y relaciones exteriores), de modo que las voluntades individuales, hacen posible el óptimo del bienestar, sin más dirección que una especie de mano invisible que guía su conducta. El valor más importante del liberalismo es la libertad, entendida como la ausencia de coerción de los individuos sobre los individuos.

6 Claude Fréderic Bastiat (1801-1850) fue un escritor, legislador y economista francés al que se le considera uno de los mejores divulgadores del liberalismo de la historia. Fue parte de la escuela liberal francesa. Su libro "La Ley" es su obra maestra. En ella afirma que la vida, la libertad y la propiedad no existen porque los hombres hubieran hecho leyes. Por el contrario, es el hecho de que la vida, la libertad y la propiedad existieran de antemano lo que causó que los hombres hicieran leyes. Él coloca la fuente de la Ley en la naturaleza humana: para vivir, los seres humanos necesitan libertad y propiedad para transformar el potencial de la naturaleza en cosas utilizables. Así, la Ley que pugna con la la libertad y la propiedad no es propiamente Ley, sino saqueo legalizado, una tentación constante, ya que los hombres desean alcanzar sus objetivos sin el más mínimo esfuerzo.

7 Friedrich August Von Hayek (1898-1992) recibió el Premio Nóbel de Economía en 1974, junto con Gunnar Myrdal por su trabajo pionero en la teoría del dinero y las fluctuaciones económicas, y por sus penetrantes análisis de la interdependencia de los fenómenos económicos, sociales e institucionales. En su obra "camino de servidumbre" sostiene que toda planificación económica, por leve que sea, se basa en la creación de un supuesto bien común que se constituye en el objetivo general. Así pues, la planificación económica conduce necesariamente hacia el totalitarismo y la pérdida de libertades individuales. En el libro, usa tanto la ex Unión Soviética como la Alemania Nazi como ejemplos de países que han recorrido el camino de servidumbre y llegado a esa situación. En sus palabras: "Cualquier política encaminada de manera directa a un ideal de justicia distributiva, es decir, a lo que alguien entienda como una distribución "más justa" tiene necesariamente que conducir a la destrucción del imperio de la Ley porque, para poder producir el mismo resultado en personas diferentes, sería necesario tratarlas de forma diferente. Y ¿cómo podría haber entonces leyes generales?.

8 Entre sus representantes: Lucas, Muth, Sargent, Wallace, Barro. Críticos de los modelos macroeconómicos keynesianos, estableciendo que los agentes tienen expectativas racionales, bajo ciertas condiciones utilizan toda la información posible. Plantean que los precios y los salarios son flexibles para garantizar un equilibrio continuo de los mercados (los mercados se autorregulan). Los supuestos fundamentales de la nueva escuela clásica son: 1) los agentes económicos tienen una conducta maximizadora; 2) las expectativas son racionales; 3 ) los mercados se vacían (los precios y salarios se ajustan para igualar la oferta y la demanda).

9 Obras conocidas: La ética protestante y el espíritu del capitalismo (1904-1905); Economía y sociedad (1922). 
Por otro lado, T. Veblen (1857-1929) considerado como el fundador del institucionalismo económico moderno o americano, criticó la esterilidad del análisis marginalista para comprender la influencia de los valores, las tradiciones, las leyes y la cultura, en la conducta económica de los individuos. Veblen postuló que en la realidad, la economía es una red de instituciones y valores que organizan y moldean el comportamiento económico de los individuos.

j. Schumpeter ${ }^{10}(1833-1950)$, desde otra perspectiva recreó el enfoque institucionalista. En su obra Theory of Economic Development (1912) introdujo el papel del liderazgo y la capacidad empresarial en la organización del mercado y en la innovación técnica. Para Schumpeter, la clave del desarrollo económico reside en la capacidad de los empresarios innovadores de crear condiciones para el progreso técnico, por ser éste el que a su vez facilita los avances sociales.

F. Knight (1885-1972) en su obra Risk, Uncertanity and Profit (1921) incorporó el concepto de incertidumbre asociado al desconocimiento económico y el modo en que éste afecta el comportamiento de los individuos. Estas ideas sirvieron a los institucionalistas para analizar los problemas de información incompleta y asimétrica, riesgo moral, selección adversa y problemas de agencia y el principal.

F. Commons, en sus obras Legal Foundations of Capitalism (1929) e Institutional Economics (1934), destacó el papel del derecho y las leyes en el comportamiento económico. Define las instituciones como una acción colectiva emprendida para ampliar la libertad y la acción individual como una condición indispensable para crear mercados libres, incluido el mercado de trabajo.
J. Stiglitz ${ }^{11}$ en sus investigaciones durante el último cuarto de siglo, ha demostrado que una de las razones de la invisibilidad de esa mano invisible es tan sencilla como que la mano no aparece por ninguna parte. Hasta en los países desarrollados, los mercados funcionan de manera distinta a lo previsto por la teoría de los mercados perfectos.

En general, estos economistas, entre otros, contribuyeron a la formación de la escuela institucionalista americana, la que se caracterizó por combinar las categorías propias del análisis económico y de la teoría de las instituciones para estudiar el impacto de las instituciones, la legislación económica, los valores y la cultura en el comportamiento económico de los individuos y grupos.

\section{Características del Neoinstitucionalismo}

El Nuevo Institucionalismo económico surge como una respuesta al institucionalismo tradicional y al mismo tiempo, como una crítica a la rigidez analítica de la economía neoclásica. No es una escuela homogénea, coexisten diversas corrientes desde las que se encuentran muy cercanas a los supuestos básicos de la economía neoclásica, hasta aquellas que rechazan sus fundamentos teóricos. Comprende autores como Coase, Williamson y North, que coinciden en destacar la importancia de las instituciones, pero al mismo tiempo existen diferencias teóricas. A los tres se les considera como los representantes del neoinstitucionalismo. Sus principales carácterísticas son:

- Establece expresamente las restricciones o limitaciones ideadas por el hombre que dan forma a la interacción humana.

10 Economista austriaco, conocido por tres de sus libros "Ciclos Económicos”, donde analiza las distintas teorías sobre las fluctuaciones en economía; "Capitalismo, socialismo y democracia", obra en la que se pronuncia sobre los dos grandes sistemas e "Historia del análisis económico”. Schumpeter pensaba que el factor fundamental en el cambio económico es el empresario innovador (o"schumpeteriano” como se dice a partir de él), entendiendo que el ciclo económico resulta perfectamente normal. Se opuso a las teorías de Keynes, sobre todo por sus consecuencias de intervencionismo del Estado en la economía.

11 En el 2001, GEORGE A. AKERLOF, A. MICHAEL SPENCE y JOSEPH E. STIGLITZ (estadounidenses), obtuvieron el Premio Nóbel de Economía "Por sus análisis de los mercados con información asimétrica". 
- Incorpora el papel del intercambio de los derechos de propiedad y los contratos que aseguran las transacciones. Estructuran incentivos en el intercambio humano, sea político, social o económico.

- Considera las consecuencias de los costos de transacción y plantea que el intercambio no es libre de costos.

- Reconoce la existencia de información incompleta y asimétrica.

- Reconoce la importancia del marco jurídico.

- Acentúa la importancia de las estructuras de poder y las organizaciones políticas.

- Acepta el papel de las acciones colectivas y la organización de los grupos sociales.

\section{LA TEORÍA INSTITUCIONAL SEGÚN DOUGLASS NORTH}

La teoría institucional surgió para suplir algunas de las falencias del análisis neoclásico para analizar políticas que lleven al desarrollo. El enfoque neoclásico se refiere a cómo operan los mercados y no a cómo se desarrollan. Modela un mundo preciso, en el cual el intercambio se da sin fricciones e ignora los incentivos.

La realidad indica que la información es incompleta, los modelos erróneos y la retroalimentación de información insuficiente. En otras palabras, en el mundo real, existen las fallas de mercado.

Douglass North ${ }^{12}$ edifica su teoría de las instituciones partiendo de una teoría de la conducta humana combinada con una teoría de los costos de transacción ${ }^{13}$ . Sostiene que cuando se combinan ambas teorías (conducta humana y costos de transacción) se puede entender por qué existen las instituciones y qué papel desempeñan en el funcionamiento de las sociedades y afirma además, que al agregar una teoría de la producción, se puede analizar las funciones de las instituciones en el desempeño de las economías.En palabras de North, el Neoinstitucionalismo es:

Un programa de investigación interdisciplina-
rio que trata explícitamente con las relaciones
entre instituciones, cambio institucional y
desempeño económico.

El análisis neoinstitucionalista es una línea de investigación que parte de la economía neoclásica, pero no la abandona. En el centro de su agenda de investigación está puesto el énfasis en los derechos de propiedad, la medición de los costos de transacción, el cumplimiento de la ley y los problemas de información incompleta. El programa de investigación ha enriquecido y fertilizado con el estudio del derecho, la ciencia política, la sociología, la antropología y la historia.

\section{Enfoque institucional de la Economía}

El análisis institucional de la Economía incorpora la Teoría de las Instituciones a la Teoría Económica. Las instituciones, están formadas por restricciones formales (definidas por el mandato de la Ley), restricciones informales (definidas por las normas o convenciones sociales) y el cumplimiento obligatorio.

12 Economista estadounidense nacido el 05/11/1920 en Cambridge (Massachusetts), profesor en la Washington University de St. Louis, Missouri. Realizó sus estudios superiores en la Universidad de California (Berkeley). Su récord universitario no fue de lo mejor. En sus palabras, tuvo sólo ligeramente mejor que una "C" media, aunque lo hizo con una importancia triple en la ciencia política, filosofía y economía. En el año de 1993 dos estadounidenses DOUGLASS NORTH y ROBERT FOGEL obtuvieron el máximo galardón en economía, "Por haber renovado la investigación de la historia económica aplicando la teoría económica y métodos cuantitativos para explicar el cambio económico e institucional”. Ambos son considerados pioneros de la llamada nueva historia económica o cliometría”.

13 Costo que se realiza para definir, proteger y hacer valer los derechos de propiedad de los bienes y/o servicios intercambiados. Son los costos en los que incurren las partes en el proceso de llegar a un acuerdo y de velar por su cumplimiento.Para hacer efectivas las transacciones, los agentes económicos deben incurrir en: a) costos de búsqueda o medición de bienes y/o servicios intercambiados (permiten definir las características de los bienes y/o servicios que se desea intercambiar); b) costos de hacer valer o cumplir los derechos de propiedad (exigibilidad de las reglas). Estos costos se realizan con la finalidad de tener seguridad jurídica, es decir, cuando se compra un inmueble se trate de propiedad de quien lo compra y podrá demostrarse ante la Ley. 
Para Roemer (1994:46) una unidad importante de análisis del nuevo enfoque institucional es el examen sitemático de la relación existente entre derechos de propiedad e instituciones $^{14}$

Los elementos del enfoque insitucional de la economía son:

- Las instituciones.

- Las organizaciones.
- Sistema de justicia que vigile el cumplimiento de la ley.

En general, el enfoque institucionalista concibe el mercado como una institución compleja, que es el resultado de los arreglos económicos, sociales e institucionales a los cuales llegan los individuos y que opera simultáneamente en la sociedad, la política y la economía.

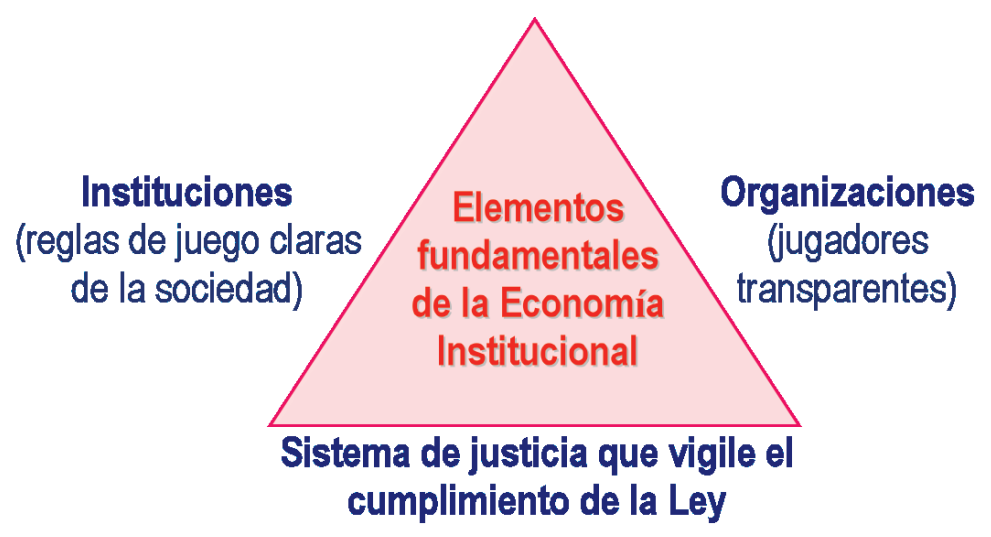

\subsection{LAS INSTITUCIONES}

Las instituciones y organizaciones afectan la economía por su influencia sobre los incentivos en el intercambio humano, los costos de transacción y los derechos de propiedad. Según D. North, define las instituciones como:

Las reglas de juego de una sociedad o más formalmente, son las limitaciones ideadas por el hombre que dan forma a la interacción humana. Por consiguiente, estructuran incentivos en el intercambio humano, sea político, social o económico. El cambio institucional conforma el modo en que las sociedades evolucionan a lo largo del tiempo, por lo cual es la clave para entender el cambio histórico (North 1993:13).
Las instituciones son la clave para entender la interrelación entre la política y la economía y las consecuencias de esa interrelación para el crecimiento económico o estancamiento de la producción. Proporcionan la estructura del intercambio (junto con la tecnología empleada) determina el costo de transacción y el costo de transformación.

Las instituciones permiten que los costos de transacción se reduzcan y en consecuencia, que el intercambio sea viable; se entiende por sociedad a la organización, en el que el intercambio y la producción ${ }^{15}$ no sólo están mediados por los mercados sino por arreglos formales e informales.

14 Los derechos de propiedad son títulos legales que rigen y amparan la propiedad, el uso y el destino de los recursos; tienen la característica esencial que pueden hacerse valer ante los tribunales. La propiedad es el poder jurídico que permite usar, disfrutar, disponer y reivindicar un bien.

15 Cesare Luporini en su obra "Karl Marx Introducción general a la crítica de la economía política” sostiene que toda forma de producción engendra sus propias instituciones jurídicas, su propia forma de gobierno, etc.

16 Las limitaciones institucionales incluyen aquello que se prohíbe hacer a los individuos y a veces, las condiciones en que a algunos individuos se les permite hacerse cargo de ciertas actividades. Por tanto, constituyen el marco en cuyo interior ocurre la interacción humana. 
En otras palabras, las instituciones son las limitaciones ${ }^{16}$-restricciones- inventadas o ideadas por el hombre para estructurar las interacciones entre los individuos. Por consiguiente, estructuran incentivos en el intercambio humano, sea político, social o económico.

Estas restricciones, conocidas por la Economía Institucional como Instituciones, reducen la incertidumbre y el riesgo por el hecho de que proporcionan una estructura a la vida diaria.

El conjunto de limitaciones institucionales puede dar como resultado varias mezclas de limitaciones formales e informales, que a su vez reflejarán lo costoso de la medición y el cumplimiento obligatorio.

Los costos de negociación son la dimensión más observable del marco institucional en que se apoyan las limitaciones del intercambio.

En síntesis, la interacción compleja de reglas formales y de limitaciones informales junto con el modo en que se hacen cumplir, determina nuestra vida diaria y nos dirige en las actividades ordinarias.

\subsubsection{Función principal de las instituciones}

La función principal de las instituciones en la sociedad es reducir la incertidumbre estableciendo una estructura estable (pero no necesariamente eficiente) de la interacción humana. Sin embargo, la estabilidad de las instituciones de ningún modo contradice que estén en constante cambio.
Las instituciones existen y reducen las incertidumbres propias de la interacción humana. Estas incertidumbres surgen como consecuencia de la complejidad de los problemas que deben resolverse. Las incertidumbres se deben a información incompleta respecto de la conducta de otros individuos en el proceso de interacción humana.

\subsubsection{Tipos de instituciones}

Existe una clasificación de las instituciones de acuerdo con su origen. Desde esta perspectiva, las instituciones pueden ser sociales y estatales. Las instituciones sociales son las convenciones que se establecen en una determinada sociedad y de creación espontánea. Las instituciones estatales son impuestas externamente a los individuos o a la colectividad en su conjunto y su cumplimiento es forzado coercitivamente por el Estado.

Hay otra clasificación de las instituciones de acuerdo con su formalización en la ley. Desde este punto de vista, las instituciones pueden ser formales e informales. La diferencia entre limitaciones informales y formales es de grado. Mientras las reglas formales pueden cambiar de la noche a la mañana -en forma abrupta- como resultado de decisiones políticas o judiciales, las restricciones informales incorporadas en las costumbres, las tradiciones y las restricciones culturales cambian gradualmente, ya que no sólo conectan el pasado con el presente y el futuro, sino que nos proveen un mecanismo para explicar la trayectoria del cambio histórico. Sin embargo, las reglas formales pueden complementar y alentar la efectividad de las limitaciones informales.

Tabla N.o 01: Características de las instituciones formales e informales

\begin{tabular}{|l|l|l|}
\hline \multicolumn{1}{|c|}{ Características } & \multicolumn{1}{|c|}{ Reglas Formales } & \multicolumn{1}{c|}{ Reglas Informales } \\
\hline Naturaleza & $\begin{array}{l}\text { Definidas por el mandato de la Ley. Cons- } \\
\text { tituciones, Leyes, Derecho Consuetudi- } \\
\text { nario, Reglamentos, regulaciones y demás } \\
\text { dispositivos legales. Incluyen reglas políti- } \\
\text { cas, judiciales, económicas y contratos. }\end{array}$ & $\begin{array}{l}\text { Definidas por convenciones sociales. Re- } \\
\text { glas no escritas y convencionales, normas } \\
\text { de comportamiento o normas sociales, có- } \\
\text { burocráticas. }\end{array}$ \\
\hline Objetivo principal & Resolver problemas específicos & Incentivar y promover valores \\
\hline Cumplimiento de reglas & Obligatorio y coercitivo & Voluntario \\
\hline Cambio de reglas & Inmediato & Gradual \\
\hline Dominio & Público & Privado \\
\hline
\end{tabular}

17 Adaptado de AYALA (2004:67). 
Las características de las instituciones formales (limitaciones formales) e informales (limitaciones informales) se pueden apreciar en la tabla siguiente ${ }^{17}$ :

\subsubsection{Limitaciones informales.}

En todas las sociedades, desde la más primitiva hasta la más avanzada, la gente se impone limitaciones para dar una estructura a sus relaciones con los demás.

Las instituciones informales son las reglas no escritas, que se van acumulando con el transcurso del tiempo y quedan registradas en los usos y costumbre. Son el resultado de la evolución de los códigos de conducta, los valores, las ideas y tradiciones de la sociedad. Estas instituciones son de autocumplimiento, ya que no se requiere de una fuerza exógena para obligar su cumplimiento y las sanciones derivadas de su incumplimiento son meramente morales y privadas. Por lo que estas instituciones se encuentran dentro del ámbito privado.

Las limitaciones informales provienen de la información transmitida socialmente y son parte de la herencia que llamamos cultura ${ }^{18}$. En la tradición latina se le conoce como derecho consuetudinario y para los anglosajones es lo que denominan el common law ${ }^{19}$. Las limitaciones informales, tales como acuerdos y códigos de conducta, provienen de información trasmitida socialmente y son parte de lo que se llama cultura. Boyd y Richerson (1985) definen la cultura como la trasmisión de una generación a la siguiente, por la enseñanza y la imitación, de conocimientos, valores y otros factores que influyen en la conducta.
Las instituciones pueden ser creadas como lo son las constituciones políticas de los Estados o también pueden evolucionar a lo largo del tiempo, tal como evoluciona el derecho consuetudinario $^{20}$

Sugden (1986) afirma que una convención o acuerdo adquiere fuerza moral cuando casi todos los miembros de la comunidad la siguen, y que a cada individuo le interesa que todas aquellas personas con quienes trata se apeguen a la norma siempre y cuando el individuo se apegue también. Según Sugden, lo que termina dándose es una "moralidad de cooperación".

\subsubsection{Limitaciones formales.}

Las instituciones formales son las reglas escritas en las leyes y reglamentos y son restricciones creadas por el hombre para resolver problemas específicos. El cumplimiento de estas reglas es obligatorio y se requiere de un poder coercitivo para hacerlas cumplir. Este tipo de instituciones son de dominio público.

La jerarquía de estas reglas, desde constituciones, estatutos y leyes comunes hasta disposiciones especiales, define limitaciones que pueden fluctuar de reglas generales a especificaciones particulares. Típicamente, las constituciones están ideadas para que resulte más costoso alterarlas que las leyes estatutarias, del mismo modo que es más costoso alterar leyes estatutarias que contratos individuales.

En el sistema político, las normas políticas definen ampliamente la estructura jerárquica del gobierno.

18 Según D. North la cultura se define como la transmisión de una generación a la siguiente, por la enseñanza y la imitación, de conocimientos, valores y otros factores que influyen en la conducta.

19 La traducción literal del término common law es “derecho común”. Es aquel utilizado en gran parte de los territorios que tienen influencia británica. Se caracteriza por basarse más en la jurisprudencia que en las leyes.

20 La evolución del derecho consuetudinario, una forma de cambio institucional, ayuda a entender el cambio institucional general. Se basa en precedentes, por ello proporciona continuidad y predecibilidad esencial que son elementos fundamentales para reducir la incertidumbre entre las partes contratantes. 
Las leyes son las que dan la legitimación esencial a todo marco de reglas formales. Sin embargo, aquellas sociedades que adoptan reglas formales de otra sociedad (como es el caso de nuestro país) tendrán características de funcionamiento muy diferente a la del país original, debido a que tanto las reglas informales como las características de imposición serán distintas. Por lo tanto, la adopción de reglas formales no constituye una condición suficiente para el buen funcionamiento y resultado económico exitoso.

Típicamente las constituciones a diferencia de las leyes estatutarias- han sido creadas para que resulte más costoso alterarlas. De igual forma, resulta más costoso alterar leyes estatutarias que contratos individuales. Los contratos contienen disposiciones específicas de un acuerdo particular. Estas reglas específicas definen derechos de propiedad, esto es, el conjunto de derechos sobre el uso $y$ el ingreso que se deriva de la propiedad y la capacidad para enajenar un valor o un recurso.

La función de las normas ${ }^{21}$ es facilitar el intercambio político o económico. El intercambio incluye negociaciones realizadas en el seno del conjunto de instituciones ya existentes, pero igualmente hay ocasiones en que los participantes consideran que vale la pena destinar recursos a alterar la estructura básica de la política para reasignar derechos.

El grado de la diversidad de los intereses económicos y políticos, dada la fuerza de negociación relativa, influirá en la estructura de las reglas. En términos generales las reglas políticas conllevan a reglas económicas, sin embargo, la relación causa-efecto obra en ambos sentidos. Esto significa que los derechos de propiedad y específicamente los contratos individuales se hacen cumplir por medio de la toma de decisiones políticas, pero la estructura de los intereses económico también influirá en la estructura política ${ }^{22}$

Es importante tomar en cuenta, que la función de las reglas formales es promover ciertos tipos de intercambio, pero no todo el intercambio.

\section{LAS ORGANIZACIONES Y EL CAMBIO INSTITUCIONAL}

Las organizaciones son grupos de personas unidas en torno a un propósito común para alcanzar determinados objetivos. Las organizaciones son los llamados agentes del cambio institucional. Andrés Suárez (1992), al referirse a las instituciones y las organizaciones sostiene lo siguiente:

La organización es el instrumento racional
del que se sirven los individuos o grupos
de individuos para realizar un determinado
trabajo, actividad o empresa. Una institución,
en cambio, es producto de las necesidades y
presiones sociales.

D. North (1993), sostiene que los agentes determinan la dirección del cambio institucional y por lo tanto, las organizaciones alteran incrementalmente la estructura institucional.

Conceptualmente es necesario diferenciar con precisión las organizaciones de las instituciones. El propósito de las instituciones es definir la forma en que el juego se desarrollará y las organizaciones son los jugadores. La interacción de ambos (instituciones y organismos) determinan la dirección del

21 Las normas son reglas de conducta; sustancia de la Ley. Significación lógica creada según ciertos procedimientos instituidos por una comunidad jurídica y que como manifestación unificada de la voluntad, regula la conducta humana en un tiempo y lugar definidos.

22 En equilibrio, una estructura de derechos de propiedad ( $y$ su cumplimiento obligatorio) será congruente con un conjunto particular de reglas políticas (y de su cumplimiento obligatorio). 
cambio institucional. Las instituciones determinan las oportunidades que hay en una sociedad y las organizaciones son creadas para aprovechar esas oportunidades, y conforme evolucionan los organismos, alteran las instituciones.

Las organizacionesincluyen:

- Organizaciones políticas: partidos políticos $^{23}$, el senado, sistemas electorales, municipalidades, poderes del Estado, entidades regulatorias.

- Organizaciones económicas: empresas, sindicatos, cooperativas, etc.

- Organizaciones sociales: iglesias, clubes, asociaciones deportivas, etc.

- Organizaciones educacionales: universidades, escuelas, institutos superiores, centros de formación profesional, etc.

Si las organizaciones dedican sus esfuerzos hacia alguna actividad improductiva, las limitaciones institucionales proporcionan la estructura del incentivo para tal actividad. Los países en vías de desarrollo son pobres porque las limitaciones institucionales definen un conjunto de liquidaciones de la actividad político-económica que no alientan la actividad productiva. Por tal razón, los países socialistas a partir de los noventa apreciaron que el marco institucional establecido era la causa de su bajo desempeño, por lo que comenzaron a adoptar formas para reestructurar su marco institucional.

La estructura de impuestos, regulaciones, decisiones judiciales y derecho escrito, son limitaciones formales que dan lugar a la política de la empresa, sindicatos y otras organizaciones, consiguientemente, determinan aspectos críticos del desempeño económico.

Ronald H. Coase ${ }^{24}$ considera muy importante el sistema legal en el mundo moderno; descubrió y aclaró la importancia de los costos de transacción y de los derechos de propiedad para el funcionamiento de la economía; específicamente, sostiene que los derechos económicos son fundamentales para la estructura institucional y el funcionamiento de la economía.

Teorema de Coase: las transacciones privadas son eficientes siempre y cuando existan derechos de propiedad bien definidos y los costos de transacción sean bajos. De manera equivalente, con derechos de propiedad y con costos de transacción bajos, no existen externalidades $^{25}$

Robert Frank (1992:707) cita a Coase quien afirma muy claramente que esta conclusión sólo era válida en un mundo en el que las partes pudieran negociar incurriendo en un costo relativamente bajo. Admitía plenamente que había numerosas externalidades importantes en las que no se satisfacía este supuesto. Para empezar, toda negociación requiere tiempo y energía, y cuando los beneficios potenciales son pequeños, puede darse el caso de que no merezca la pena. Hay situaciones por el contrario, en las que único contaminador causa daños a un gran número de personas. Negociar con grandes grupos es inherentemente difícil y costoso, y todos los miembros del grupo tienen poderosos incentivos para no pagar estos costos.

23 Max Weber en su obra "Economía y sociedad" denomina partidos a las formas de "socialización" que descansando en un reclutamiento (formalmente) libre, tienen como fin proporcionar poder a sus dirigentes dentro de una asociación y otorgar por ese medio a sus miembros activos determinadas probabilidades ideales o materiales (la realización de fines objetivos o el logro de ventajas personales o ambas cosas). Pueden ser formas de socialización efímeras o de cierta duración, y aparecer como asociaciones de toda clase y forma.

24 Ronald H. Coase (Gran Bretaña) obtuvo el Premio Nóbel de Economía en el año 1991 "Por su contribución al esclarecimiento de la importancia de los costos de transacciones y de los derechos económicos para la estructura institucional y el funcionamiento de la economía”.

25 Las externalidades son aquellas actividades que afectan a terceros, positiva o negativamente, sin que éstos (beneficiados o afectados) paguen o sean pagados por dichas actividades respectivamente. Un ejemplo de externalidad negativa es la contaminación. 
El planteamiento de Coase abrió el campo del Derecho y la Economía; ha permitido el surgimiento de una nueva rama de estudio: el Derecho Económico; el mismo que se concibe como las reglas de juego que rigen el sistema económico. Como es de entender, lo que se intercambia en el mercado no son únicamente bienes físicos sino también derechos que las personas tienen sobre diversos activos establecidos en el sistema legal. Los derechos de propiedad legal son el medio a través del cual el Estado asigna derechos económicos ${ }^{26}$

Hernando De Soto (2000), en su obra "El Misterio del Capital" sostiene que: "Es preciso entender un punto crucial: la propiedad no es algo físico... La propiedad no es una cualidad primaria de los activos sino la expresión legal de un consenso económicamente significativo acerca de ellos. La Ley es el instrumento que fija y realiza el capital... La propiedad no consiste en los activos mismos sino en el consenso entre personas respecto de cómo estos deben ser poseídos, utilizados e intercambiados".

El planteamiento central de la obra de Hernando De Soto es que en los países subdesarrollados hay diversos activos físicos no utilizados, hace referencia a un "capital muerto" que si fuera usado, dichos países podrían desarrollarse. El principal obstáculo para que el "capital muerto" se convierta en "capital vivo" es un sistema socio-político que combina la lentitud política y burocrática del Estado, la falta de información y la ausencia de un sistema legal de propiedad. Este diagnóstico lo lleva a plantear un conjuntode recetas de reformas neoliberales, tanto en el plano político como institucional.
Consecuentemente, estudiar cómo las organizaciones económicas, políticas, sociales, educacionales impulsan el cambio y el fortalecimiento institucional exige una interacción de la ciencia económica con las demás ciencias sociales.

\section{SISTEMA JUDICIAL QUE VIGILE EL CUMPLIMIENTO DE LA LEY}

Ninguna institución es necesaria en un mundo de información completa, sin embargo, en un mundo real, caracterizado por la información incompleta, las soluciones cooperativas se descompondrán a menos que se creen instituciones que proporcionen suficiente información.

El cumplimiento obligatorio por una tercera parte significa el desarrollo del Estado como una fuerza coercitiva capaz de monitorear derechos de propiedad y hacer cumplir contratos. El cumplimiento obligatorio por una tercera parte requiere de una parte neutral con la aptitud de poder medir, sin costo, los atributos de un contrato y, también sin costo alguno hacer cumplir acuerdos de tal modo que la parte ofensora siempre tuviera que compensar a la parte dañada en forma tal que le resultara muy costoso violar el contrato.

Si el Estado posee la fuerza coercitiva, entonces quienes rijan al Estado utilizarán esa fuerza en su propio interés a expensas del resto de la sociedad.

Es preciso destacar que crear un medio institucional que induzca un compromiso creíble requiere un marco institucional completo de normas formales, de limitaciones

26 Juan Farina (1997) define al Derecho Económico como el conjunto de normas que rigen la organización de la economía por los poderes públicos y regulan las actividades económicas de las personas privadas y del Estado, a fin de dar cumplimiento a la política económica puesta en práctica por el Estado, como poder político, conforme a la ideología adoptada al respecto. El Derecho Económico está ligado, pues, la ideología adoptada por el Estado en materia de política económica. Por ello existen, por lo menos teóricamente, dos grandes grupos de Derecho Económico: el Derecho Económico de los países de economía capitalista (liberal, neoliberal) y el Derecho Económico de los países de economía socialista (planificación centralizada). Por lo tanto, el Derecho Económico es el conjunto de normas por medio de las cuales el Estado pone en práctica la política económica conforme a la ideología adoptada. 
informales y de cumplimiento obligatorio todo lo cual permite hacer transacciones a bajo costo.

En los países desarrollados, los sistemas judiciales incluyen cuerpos legales bien especificados y agentes idóneos -abogados, jueces, jurados, y fiscales- que ofrecen alguna confianza de que los méritos del caso, en lugar de las recompensas individuales, influirán en los resultados. En contraste, la aplicación de la ley en las economías del Tercer Mundo es incierta, no sólo por causa de la ambigüedad de la doctrina legal (un costo de medición), sino también por la incertidumbre con relación al comportamiento de los agentes.

La existencia de un sistema judicial que funcione adecuadamente es un requisito indispensable tanto para el funcionamiento del Estado de Derecho como para el desarrollo económico de un país. En el marco de la teoría institucional ${ }^{27}$ , el sistema judicial es el mecanismo fundamental para garantizar el cumplimiento de las reglas de juego que deben facilitar las actividades y transacciones de los agentes económicos.

La función general del Poder Judicial consiste en, de un lado, interpretar y aplicar las reglas de juego determinadas por el marco normativo de acuerdo a procedimientos establecidos $y$, de otro lado, identificar las inconsistencias entre las reglas específicas y la Constitución ${ }^{28}$ Un sistema judicial imparcial y eficiente es importante para la economía y, en general, para la vida social de un país, pues debe hacer efectivas las reglas de juego que permiten a los agentes desempeñarse en un entorno de certidumbre y de garantía de los derechos. La reforma debe buscar un Poder Judicial con justicia rápida, eficaz y eficiente, que sea independiente del poder político.

INSTITUCIONES, TEORÍA ECONÓMICA Y DESEMPEÑO ECONÓMICO

Para North, las instituciones son importantes para el desempeño económico porque representan el marco en el cual los individuos actúan y realizan elecciones. Argumenta que las instituciones cumplen un papel crucial en la dinámica y desarrollo de cualquier sistema económico.

El desempeño económico es un resultado de la interacción entre organizaciones políticas, económicas, sociales y educativas con las instituciones existentes. Sin embargo, el sistema político conduce a la selección de las instituciones formales, éstas determinan la selección del tipo de organización económica y el desempeño económico.

Por el contrario, aquellas sociedades que históricamente han sido incapaces de desarrollar instituciones estables que fomenten los intercambios eficientes y la productividad presentan, comparativamente, menores tasas de crecimiento económico.

\section{EL DESEMPEÑO ECONÓMICO: NEOCLÁSICOS VS. NEOINSTITUCIONALISTAS}

En la Teoría Neoclásica, el desempeño de la economía es una función de los precios de los factores de la producción, Tierra $(\mathrm{T})$, Trabajo $(\mathrm{W})$ y Capital $(\mathrm{K})$, es decir: $\quad$ Desempeño económico $=\mathrm{f}(\mathrm{T}, \mathrm{W}, \mathrm{K})$.

27 La tesis central de este marco teórico es que las instituciones son el factor determinante del desempeño de las economías. En esa línea, para lograr el crecimiento económico sostenido se requiere la existencia de reglas de juego que faciliten las actividades y transacciones y de mecanismos que las hagan cumplir efectivamente.

28 Víctor García (2008:410) cita a Reynaldo VANOSSI quien señala que "La Constitución es el enunciado institucional de las grandes reglas de juego político y social que una comunidad adopta, para un cierto tiempo de su devenir histórico, por medio de un determinado reparto de competencias y con proyección u orientación hacia ciertos fines en los que la sociedad visualiza su porvenir". 
En cambio, para los neoinstitucionalistas el desempeño económico es un resultado de los precios relativos de los factores de la producción, pero también de los diversos conjuntos institucionales $\mathrm{Q}_{\mathrm{n}}$, es decir: Desempeño económico $=\mathrm{f}$ $\left(\mathrm{T}, \mathrm{W}, \mathrm{K}, \mathrm{Q}_{1} \ldots \ldots \mathrm{Q}_{\mathrm{n}}\right)$.

La variable $Q_{\text {, }}$, representa diferentes conjuntos institucionales cuya definición depende, en último término, del Estado, por ejemplo, derechos de propiedad $\mathrm{Q}_{1}$, contratos $\mathrm{Q}_{2}$, etc.

Según North, la Teoría Neoclásica del crecimiento deja de lado todas las cuestiones interesantes, ya que depende de la existencia de una estructura de incentivos para que funcione el mecanismo de acumulación de capital y conocimiento, aquel que, según dicho modelo explica los rendimientos crecientes y el crecimiento resultante.

La estructura que crean los seres humanos (compuesta de instituciones: reglas formales, normas informales y las características para garantizar su cumplimiento) para ordenar su medio ambiente político y económico es el determinante básico del desempeño económico. Sin embargo, la productividad es la causa del mejor desempeño económico (North 2007:81).

\section{INTERCONEXIÓN DE LAS ORGANIZACIONES POLÍTICAS Y ECONÓMICAS CON LAS INSTITUCIONES EXISTENTES}

El desempeño económico es un resultado de la interacción entre organizaciones políticas y económicas con las instituciones existentes.

El proceso político conduce a la selección de las instituciones formales, éstas determinarán la selección del tipo de organización económica y el desempeño económico. Sin embargo, si los programas o planteamientos de la clase política no son correspondientes con las reformas económicas, sociales y con las expectativas de la población en general, los partidos políticos tienden a desaparecer o simplemente, se convierten en un grupo de personalidades o partido de "personas notables".

Las organizaciones políticas dan forma al crecimiento económico ya que definen y refuerzan las reglas. Se entiende que los organismos políticos pueden ser estables sólo si cuentan con el apoyo de marco institucional que tiene el interés en perpetuarlas. Por ello, un aspecto fundamental de las reformas políticas y económicas es la creación de tales organizaciones que creen $y$ refuercen eficientemente los derechos de propiedad29.

Diagrama N.o 02: Interconexión de las organizaciones políticas y económicas con las instituciones existen-

tes

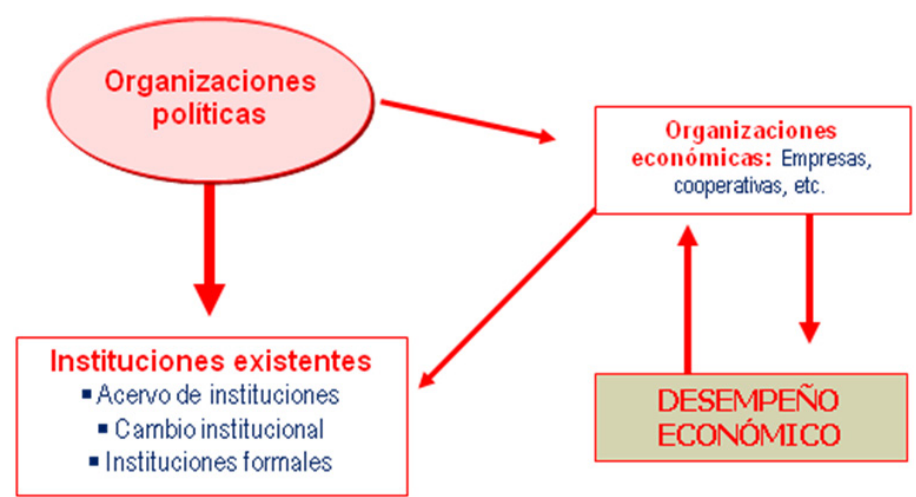

29 Los sistemas electorales, los partidos políticos, en general, las reglas o procedimientos de las legislaturas emergen en el tiempo para disminuir los costos de transacción de hacer política. Al mismo tiempo, estas reglas estructuran las interacciones entre ciudadanos, políticos y aspirantes a políticos suministrando incentivos y sanciones por comportarse de cierta forma y por distribuir el poder de negociación de manera diferencial. El comportamiento de los actores políticos se vuelve predecible en el tiempo en la medida en que se ajusta a esos incentivos, sanciones y relaciones de poder. 
Conforme evolucionan las organizaciones, también lo hacen las instituciones. El cambio en las instituciones proviene de las percepciones de los empresarios políticos y económicos. Si los mercados políticos y económicos son eficientes, las elecciones serán eficientes y las instituciones también. En el mundo real los mercados económicos rara vez son eficientes; los mercados políticos nunca lo son.

Por lo tanto, las instituciones son importantes para el desempeño de las economías porque representan el marco en el cual los individuos actúan y realizan elecciones.

\section{DEBILIDAD INSTITUCIONAL EN EL PERÚ}

Paul Krugman (2009:41) sostiene que durante generaciones, los países de América Latina estuvieron sujetos de manera casi única a las crisis de la moneda, las quiebras bancarias, los brotes de hiperinflación y todas las demás calamidades monetarias conocidas por el hombre moderno. Unos gobiernos democráticamente elegidos pero débiles alternaban con regímenes militares fuertes, ambos dedicados a comprar el apoyo popular con programas populistas que no tenían como pagar. Con el fin de financiar estos programas, los gobiernos acudían ya fuera al endeudamiento con negligentes banqueros extranjeros cuyo resultado final era una crisis de la balanza de pagos y el no pago de la deuda, o bien a la imprenta, generando como resultado final una hiperinflación.
Para Wiese (2003:73), la magnitud de la crisis que irrumpió a finales del decenio de 1980 en Argentina, Brasil y Perú obligó a los diseñadores de política a volver al gabinete de diseño para lanzar un nuevo conjunto de medidas de estabilización macroeconómica y ajuste estructural. Si bien existió un acuerdo al interior de estas sociedades civiles sobre la necesidad de un cúmulo mayor de reformas del mercado encarnadas en el Consenso de Washington (...).

Las políticas del Consenso de Washington $^{30}$ fueron diseñadas para responder a problemas muy reales de América Latina, y tenían mucho sentido. En los años ochenta los Gobiernos de América Latina habían tenido a menudo grandes déficits. Las pérdidas en las ineficientes empresas públicas contribuyeron a dichos déficits. Aisladas de la competencia a medidas proteccionistas, las empresas privadas ineficientes forzaron a los consumidores a pagar precios elevados. La política monetaria laxa hizo que la inflación se descontrolara. Los países no pueden mantener déficits abultados y el crecimiento sostenido no es posible con hiperinflación. Se necesita algún grado de disciplina fiscal.

La crisis de las instituciones o debilidad institucional se da fundamentalmente cuando existe corrupción del sector público y privado, la calidad del sistema jurídico se deteriora, los índices de incumplimiento de la ley se incrementan, la inseguridad pública tiende a aumentar y los índices de gobernabilidad em-

30 La austeridad fiscal, la privatización y la liberalización de los mercados fueron los tres pilares aconsejados por el Consenso de Washington durante los años ochenta y noventa. Stiglitz afirma que estas ideas de fundamentalismo de mercado se reflejaban en la estrategia básica para el desarrollo defendida a principios de los ochenta por el FMI, el Banco Mundial y el Tesoro de EEUU, una estrategia que muchos bautizaron como "neoliberalismo" o, debido a que sus principales defensores se encontraban todos en Washington, "el Consenso de Washington". Stiglitz reaccionó en forma violenta contra la rigidez de las recomendaciones del FMI, por considerar que están construidas sobre la base de un modelo único y que, por ende, muchas veces no se adaptan a la particularidad de cada país. El FMI propició enérgicamente la privatización y la liberalización, a un ritmo que a menudo impuso costos apreciables sobre países que no estaban en condiciones de afrontarlos. Para algunos analistas, lo que le faltó al Consenso fue una mayor preocupación por las INSTITUCIONES POLÍTICAS que son las que, en última instancia, van a mantener y eventualmente impulsar las reformas orientadas a promover la inversión privada, la eficiencia económica y el desarrollo de los mercados.

De acuerdo con la visión de la Nueva Economía Institucional, las reformas impulsadas por el Consenso de Washington han sido en sí mismas coherentes y adecuadas con el desarrollo de la economía de mercado. Lo que ha faltado es lo que algunos han llamado reformas de segunda generación, aquellas destinadas a hacer cumplir los derechos de propiedad y a darle estabilidad al sistema político para impedir corrupción y populismo. 
peoran. Constituye un óbice para cualquier intento de crecimiento económico sostenido. Puede tornar menos seguros los derechos de propiedad. En contextos de alta volatilidad institucional, los derechos de propiedad son materia de permanente discusión y redefinición.

La integración social tropieza con serios impedimentos que tienen su lógico correlato en las instituciones. La mayoría de estas no han podido funcionar adecuadamente debido al bloqueo de los procesos de interacción sociopolíticos, a su deslegitimación de parte de la ciudadanía por inoperantes y corruptos y a su deterioro organizativo.

Las crisis han tenido como elemento generador la asimetría entre la capacidad de las instituciones para organizarse, modernizarse y responder a las demandas sociales, económicas y políticas de los habitantes.

La historia política de nuestro país evidencia un comportamiento autoritario y vertical, sin embargo, cuando se han dado espacios democráticos, la población ha mostrado una clara inclinación hacia la democracia y el consenso. Se requiere una sociedad civil organizada, una economía competitiva más distributiva y sobre todo un Estado eficaz, eficiente y moderno que se podría plantear en un proceso de democracia, con una modernización productiva y la legitimación de sus instituciones.

Cabe precisar, que la debilidad institucional en el Perú se debe no sólo a los evidentes defectos de las políticas populistas y liberales sino sobre todo a la falta de competencia y a la crisis de los partidos políticos, lo que ha devenido en el surgimiento de independientes sin trayectoria política, quienes no han sido capaces de convertirse en partidos políticos estructurados que les asegure una mayor permanencia; por el contario, se caracterizaron por perder representatividad en poco tiempo. Para fortalecer los partidos políticos, es necesario modificar el término de organizaciones polí- ticas acuñado en la Constitución de 1993, ya que ésta debilita el sentido inicial de la Ley de Partidos Políticos -Ley No 28094- que pretendía ser exclusiva para partidos políticos, a diferencia de la actual Constitución en la que se incluye como término confuso y genérico el de organizaciones políticas, además de los términos partidos políticos, movimientos y alianzas.

En esa misma perspectiva, la falta de competencia política pre y pos electoral, limita el establecimiento de reglas de juego claras en la sociedad peruana, ya que a lo largo de nuestra historia los partidos se caracterizaron por tener dos defectos: la del partido hegemónico no competitivo y la del pluripartidismo exacerbado no competitivo. Es necesario construir un sistema de partidos políticos que no esté conformado por un solo partido ni muchos, sólo los necesarios para garantizar la estabilidad política y los regímenes democráticos.

Por otro lado, la decadencia de los partidos políticos y el pragmatismo político debilitan las instituciones políticas, ya que éstos no ejercen sus funciones de mediación y representación como resultado de no contar con una organización permanente, además se encuentran conformados por agrupaciones minoritarias que difícilmente logran alianzas y acuerdos duraderos, que mayoritariamente no ejercen la democracia interna, que tienden a fragmentarse, que no logran formular posiciones de largo plazo para el país y que no cuentan con credibilidad frente a la población.

\section{LA CORRUPCIÓN}

En general, la palabra corrupción proviene del latin rumpere y se refiere a quebrantar códigos, leyes y normas de buen comportamiento cívico. El término también se refiere al deterioro en las formas de gobierno de un país, ciudad o unidad territorial ${ }^{31}$.

31 De acuerdo con el Diccionario de la Real Academia Española, una acepción del vocablo corrupción está referida a las organizaciones, especialmente en las públicas, como la práctica consistente en la utilización de las funciones y medios de aquellas en provecho, económico o de otra índole, de sus gestores. 
Concepciones más amplias de corrupción, que no implican necesariamente un pago monetario directo, serían el clientelismo, el tráfico de influencias y el uso de la discrecionalidad que da el poder estatal para beneficio del agente que entra en esta práctica.

El fenómeno de la corrupción está estrechamente ligado a fallas institucionales del Estado. La concepción tradicional del fenómeno es centrarse en la "corrupción burocrática", en la que son los funcionarios públicos los agentes que practican la corrupción. Sin embargo, ésta puede afectar al poder legislativo (corrupción legislativa), al poder judicial (corrupción judicial) y alcanzar a altos dirigentes y líderes políticos (corrupción política).

Naturalmente, no todos los Estados ni todos los funcionarios, son afectados por la corrupción. Además, todo Estado, por lo general, tiene algún sistema de contrapesos y control para evitar el abuso de poder y el mal uso de los recursos públicos. Para eso están las contralorías, el parlamento, el poder judicial y el llamado "cuarto poder" -la prensa-, los que pueden jugar un rol muy importante en denunciar y combatir la corrupción.

La ley puede ser muy estricta y clara en tipificar casos de corrupción, pero si no se aplica, esta será inefectiva. Existen básicamente tres formas de medir la corrupción:

a. A través de encuestas de percepción de corrupción realizadas a inversionistas privados nacionales, inversionistas extranjeros, funcionarios del Estado y público en general.

b. Por la recopilación de estadísticas asociadas a denuncias y procesos judiciales relacionados con prácticas de corrupción. Parte de esta información puede provenir de la prensa, de archivos judiciales u otras fuentes.

c. Por encuestas a personas a quienes se les pregunta sobre sus experiencias personales sobre pagos requeridos por funcionarios del Estado.

\section{TIPOS DE CORRUPCIÓN}

Solimano et al. (2008:12-13) identifican los siguientes tipos de corrupción:

- Corrupción en el Estado.- es la concepción más común de corrupción y se le identifica como aquella que involucra a funcionarios, agencias y organismos del Estado, ya sea a nivel centralizado o descentralizado.

- Corrupción política.- este tipo de corrupción afecta a ciertos miembros de partidos políticos que buscan extraer recursos del Estado y explotar posiciones de influencia para fines de financiamiento de partido o de enriquecimiento personal.

- Corrupción en el sector privado.- la corrupción no sólo es privativa del sector público. También se observa en el sector privado tanto en corporaciones como en otros entes privados. Así, los ejecutivos máximos de empresas privadas pueden sacar ventajas de la existencia de información asimétrica sobre materias esenciales del funcionamiento de una empresa o de información sobre oportunidades de negocio que debieran ser de carácter público. También puede estar asociada a obtener un tratamiento tributario favorable.

- Corrupción en el sector no gubernamental.- situaciones de corrupción que están sujetas a franquicias tributarias y que reciben donaciones.

\section{FACTORES QUE PUEDEN CONTRIBUIR A LA CORRUPCIÓN}

- Existencia de regulaciones excesivas y autorizaciones que les dan una gran discrecionalidad a funcionarios del Estado.

- Poca transparencia en las compras y contratos de agencias del Estado. 
- Favoritismo.

- Clientelismo.

- Nepotismo.

- Politización excesiva de la administración pública.

\section{FORTALECIMIENTO INSTITUCIONAL EN EL PERÚ}

Para lograr el desarrollo económico, no se puede prescindir de un sistema jurídico estable y reglas de juego claras de la sociedad (importancia de las instituciones y organizaciones) en que deben operar los diversos agentes económicos. Requiere especial atención el respeto de los derechos de propiedad legal en oposición contra aquello que signifique su violación, como por ejemplo las expropiaciones, incumplimiento de contratos, etc.

Sin embargo, una de las causas fundamentales por las cuales, las instituciones son ineficaces o débiles, es la falta de competencia política. Se carece de un sistema político (conjunto de organismos políticos) que promueva el Estado de Derecho. El crecimiento a largo plazo requiere del desarrollo del Estado de Derecho.

La crisis de los partidos políticos tiene como manifestación más visible el surgimiento de independientes como protagonistas en la escena política. Las opciones políticas más exitosas en los últimos años han estado basadas en liderazgos personales, como puede apreciarse en los resultados de elecciones municipales, presidenciales y en general, los procesos electorales llevados a cabo desde muchos años atrás, en los que vencieron candidatos independientes. Sin embargo, estas agrupaciones no han sido capaces de, o no les interesa, convertirse en organizaciones políticas más estructuradas, que pudieran aspirar a una mayor permanen- cia y por lo tanto, pierden la representatividad en poco tiempo.

La carencia o debilidad del sistema político hace difícil predecir la identidad de los gobiernos futuros, lo cual conlleva a que los inversionistas trasladen sus recursos a medios institucionales más predecibles o más seguros.

Para lograr una reforma institucional de éxito, resulta imprescindible cambiar las instituciones y los esquemas de creencias y valores, ya que son los modelos mentales de los agentes los que determinan las decisiones. Asimismo, es necesario que el Estado cumpla su rol y haga prevalecer fundamentalmente, la supremacía de la Ley, el respeto por la Ley y la seguridad jurídica. La piratería existe porque el riesgo de delinquir es relativamente bajo comparado con el beneficio obtenido. Si la matriz institucional recompensa la piratería, entonces aparecerán organizaciones piratas. Por ello, es imprescindible una actitud coercitiva responsable por parte del Estado.

Hace falta un marco legal que limite constitucionalmente el poder de los gobiernos de turno, la reforma de la administración de justicia (sistema judicial independiente y eficaz), la reforma de la capacidad de fiscalización del Poder Legislativo y la reforma educativa (las instituciones educativas son los caminos de bienestar y libertades personales). Todo esto requiere del gobierno; también, es importante tener en cuenta que un gobierno muy opresivo no es la única razón que imposibilita los mercados; generalmente, el problema radica en un gobierno demasiado débil.

\section{REGLAS DE JUEGO CLARAS}

Son aquellas instituciones, restricciones o limitaciones necesarias para darle estabilidad al sistema económico. Generalmente, el funcio- 
namiento de las empresas y en general de los agentes económicos se encuentra determinado por leyes, las cuales son necesarias que se cumplan para que la actividad económica se pueda desarrollar eficientemente en un contexto de competencia justa.

D. North sostiene que toda actividad organizada por los hombres entraña una estructura destinada a definir "la manera de jugar el juego", se trate de una actividad deportiva o del funcionamiento de una economía. Esa estructura está compuesta de instituciones: reglas formales, reglas informales y las características para garantizar su cumplimiento (...). Las características que crean los seres humanos para ordenar su medio ambiente político y económico es el determinante básico del desempeño económico.

\subsubsection{Importancia del marco institucional} en la estabilidad política, económica y social

Cualquier reforma que tenga como finalidad lograr un desarrollo económico sustentable, debe primero establecer un marco institucional que genere estabilidad política, económica y social. Un Estado que ejerce su poder de forma discrecional desincentiva la calidad y eficiencia inversiones y el gasto social, considerados esenciales para alcanzar un desarrollo económico sostenido en el tiempo. Son los Poderes del Estado (Ejecutivo, Legislativo y Judicial) los que determinan el funcionamiento económico, porque ellos definen e imponen reglas de juego de la sociedad. Por esta razón, el objetivo fundamental del desarrollo económico de un país debe consistir en la creación de un Estado que establezca e imponga derechos de propiedad eficientes.

\subsubsection{Reglas de juego fundamentales del Neoinstitucionalismo}

- Garantizar los derechos de propiedad. La garantía de los derechos de propiedad es indispensable para el desarrollo económico. Sin ella, los agentes económicos no tendrían incentivo alguno para adquirir propiedades e invertir en ellas, pues correría el riesgo de perderlas.

- Garantizar el cumplimiento de los contratos. Es importante que el Estado vele por el cumplimiento de los contratos o acuerdos con la finalidad de que los agentes económicos se sientan seguros. Si el Estado no garantiza que los contratos se cumplan, la actividad económica se reducirá, ya que nadie se atreverá a correr el riesgo de ser estafado impunemente.

- Reducir los costos de transacción. Es muy importante que el intercambio o las transacciones económicas sean más eficientes, para lo cual resulta necesario reducir tanto los costos de búsqueda como los costos de hacer valer los derechos de propiedad.

- Atenuar los problemas de información. Es necesario atenuar los problemas de información asimétrica, para lo cual se debe buscar una mayor transparencia de la información que existe en el mercado.

5.1.3 Reglas de juego de carácter económico establecidas en la Constitución de 1993

- Las principales reglas de juego de carácter económico establecidas en nuestra constitución son las siguientes:

- Iniciativa privada libre dentro de una economía social de mercado. De acuerdo con lo dispuesto por la Constitución vigente, nuestra economía de mercado debe ser social, en el sentido de que ciertos excesos del mercado deben ser regulados para garantizar el bien común. Es así que el artículo 58 de la Constitución establece que "La iniciativa privada es libre. Se ejerce en una economía social de mercado. Bajo este régimen, el Estado orienta 
el desarrollo del país, y actúa principalmente en las áreas de promoción de empleo, salud, educación, seguridad, servicios públicos e infraestructura”.

- Libertad de empresa, comercio e industria. El primer párrafo del artículo 59० de la Constitución establece que "El Estado estimula la creación de riqueza y garantiza la libertad de trabajo y la libertad de empresa, comercio e industria. El ejercicio de estas libertades no debe ser lesivo a la moral, ni a la salud, ni a la seguridad pública...". La creación de riqueza es una de las fuentes de progreso de los pueblos. Por eso el Estado debe estimularla. La libertad de trabajo y las de empresa, comercio e industria son consistentes con la iniciativa privada libre tipificadas en el artículo $58^{\circ}$ de la Constitución.

- Igual tratamiento legal a la actividad empresarial, pública o no pública. No hay privilegios para la actividad empresarial privada ni pública. Pueden coexistir varios tipos de empresa simultáneamente: privadas, públicas, nacionales, extranjeras, mixtas, autogestionarias, cooperativas, etc.

- Libre competencia. La libre competencia es un principio sobre el cual se inspira una economía de mercado. Se basa en la libre concurrencia de la oferta y la demanda, precios libres y ganancias libres; esto es, productores y consumidores concurren al mercado en igualdad de condiciones, de tal manera que los más eficientes tienen la posibilidad de hacer mejores negocios. Además, el Estado debe combatir toda práctica que limite la libre competencia, así como el abuso de posiciones dominantes o monopólicas, las cuales también limitan o pueden limitar la libre competencia.

- Libertad de contratar. Garantiza que las partes pueden pactar válidamente según las normas vigentes al tiempo del contrato. Los términos contractuales no pueden ser modificados por leyes u otras disposiciones de cualquier clase. Esto quiere decir que cualquiera puede contratar con fines lícitos, siempre que no se contravengan leyes de orden público ${ }^{32}$.

- Igualdad jurídica de la inversión. Esto significa que la inversión nacional y extranjera se sujetan a las mismas condiciones. La producción de bienes y servicios y el comercio exterior son libres. El comercio exterior comprende las exportaciones e importaciones ${ }^{33}$.

- Defensa de los consumidores y usuarios. El Estado defiende el interés de los consumidores y usuarios. Garantiza el derecho a la información sobre los bienes y servicios que se encuentran a su disposición en el mercado.

- Derecho de propiedad inviolable. El principio del respeto a la propiedad se consa-

32 En el artículo $62^{\circ}$ de la Constitución se garantiza que las reglas que regularon el contrato cuando fue realizado, no pueden ser modificadas posteriormente por el Estado. En esa perspectiva el segundo párrafo del artículo 620 de nuestra Constitución dispone que "Mediante contratos-ley el Estado puede establecer garantías y otorgar seguridades. No pueden ser modificados legislativamente. ...”. Los contratos ley son acuerdos del Estado con inversionistas privados, nacionales o extranjeros, a los que en el contrato se les otorgan determinadas seguridades, generalmente de política económica o de naturaleza tributaria. Nuestra Constitución establece que estos contratos ley tampoco pueden ser modificados legislativamente.

33 La primera parte del artículo $63^{\circ}$ de la Constitución dispone la igualdad jurídica de la inversión extranjera y nacional. Sin embargo, el artículo $71^{\circ}$ establece que “... dentro de $50 \mathrm{~km}$ de las fronteras, los extranjeros no pueden adquirir ni poseer, por título alguno, minas, tierras, bosques, aguas, combustibles ni fuentes de energía, directa ni indirectamente, individualmente ni en sociedad, bajo pena de perder en beneficio del Estado, el derecho así adquirido. Se exceptúa el caso de necesidad pública expresamente declarada por Decreto Supremo aprobado por el Consejo de Ministros conforme a ley”. Por lo tanto, lo establecido en el artículo 71 constituye una excepción constitucional al principio de igualdad de tratamiento a la inversión nacional y extranjera. 
gra de manera precisa en nuestra Constitución. La propiedad es el derecho real -porque constituye una relación entre una persona y una cosa- más completo que existe ya que contempla todas las prerrogativas o facultades que tiene el propietario o dueño: usar, disfrutar, disponer y reivindicar (exigir, reclamar) un bien cuando otro las usurpa. Estas facultades son las que la ley civil designa con el nombre de dominio, sinónimo de propiedad. Sin embargo, la propiedad, según nuestro ordenamiento jurídico, no es un derecho absoluto: debe ejercerse dentro de los límites de la ley y en armonía con el bien común. A nadie puede privarse de su propiedad sino por causa de seguridad nacional o necesidad pública (causa declarada por ley) y previo pago en efectivo de indemnización justipreciada.

\section{SISTEMA POLÍTICO DEMOCRÁTICO}

Jaime Joseph (2005:246-8) argumenta que el término sistema político democrático alude a los actores principales en el juego político y a las relaciones entre ellos. La política democrática es sistémica de modo que cualquier cambio en uno de los componentes re- quiere cambios sincronizados en los demás, a menos que el sistema colapse.

Asimismo, considera que el sistema puede ser representado en un diagrama, ubicando a los actores principales: la sociedad y sus organizaciones; el Estado en su capacidad ejecutiva; y las entidades deliberativas, tanto partidarias como estatales como el Congreso de la República, las asambleas regionales y los concejos municipales. Los espacios públicos son instancias flexibles y móviles al interior del sistema que vinculan a todos o a algunos de los actores.

Este diagrama simboliza a los actores principales y sus relaciones con los espacios de participación, los espacios públicos. La pirámide refleja la finalidad de la democracia: garantizar la libertad de los ciudadanos y garantizar el desarrollo humano, entendiendo esto último como la expansión en libertad de las capacidades de las personas.

Por sociedad se entiende todos los actores, organizaciones, asociaciones, corporaciones e individuos que están activos en un espacio geopolítico determinado

Los actores políticos deliberativos son los actores e instancias dedicados a la actividad deliberativa en la escena política formal a nivel nacional y local. Se tienen a los partidos políticos, el Congreso y sus miembros que son los políticos.

Diagrama N.o 03 : Pirámide del sistema político democrático, espacio público cerca del punto que representa el enfoque al desarrollo humano.

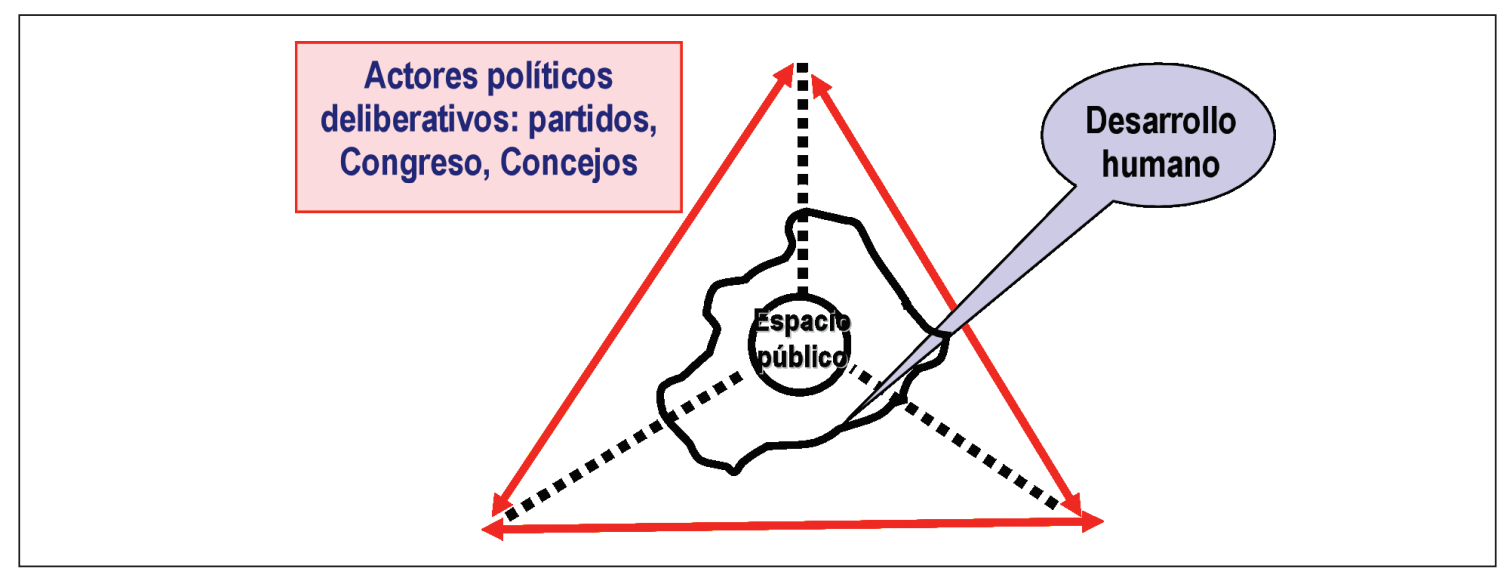

102/ QUIPURAMAYoc | Vol. 19(36) 2011 
El Estado ejecutor se refiere principalmente a las instancias ejecutivas y judiciales, encargadas de promover y crear condiciones para el desarrollo, garantizar los derechos de los ciudadanos y mantener el orden constitucional, el respeto de las leyes. El Estado ejecutor funciona en varios niveles: nacional, regional y municipal.

El círculo del centro representa un enfoque de desarrollo humano integral, que es el objetivo de las tres instancias de la pirámide. El espacio público representa a las instancias y dinámicas donde diversos actores, principalmente sociales, están interactuando para enfrentar problemas y proponer soluciones de mayor complejidad y de plazo más largo. En este caso concreto se ha ubicado al espacio público cerca al punto de la sociedad para simbolizar que la dinámica y los elementos de cultura política operativos están aún muy pegados a las demandas particulares y de corto plazo, características del nivel micro.

En las ciudades están presentes y actúan las fuerzas de violencia y caos, pero también las de paz y transformación democrática. Es sobre todo en ellas donde están emergiendo nuevas formas democráticas de hacer política y de buscar, en libertad, el desarrollo humano.

\subsubsection{Los partidos políticos en el Perú}

De todas las organizaciones políticas -considerados como los principales agentes del cambio institucional- los partidos políticos cumplen un rol fundamental, ya que éstos tienen como fin el poder. Sin embargo, los partidos políticos en nuestro país tienen un índice de confianza relativamente bajo, lo cual se debe principalmente a la poca credibilidad que los mismos inspiran.

Pérez Serrano (1984) sostiene que el partido político constituye un conjunto, un grupo coherente, una organización de ciudadanos. $Y$ nace para la acción política, para la conquista del poder y para desempeñar luego las funciones de gobierno.
José Luis Sardón (1994) define los partidos políticos como "Las agrupaciones de ciudadanos con ideas e intereses políticos comunes, que ejercen el poder o aspiran a ejercerlo a través de medios democráticos".

Marcial Rubio (1997) los caracteriza de la manera siguiente:

- Son aparatos con institucionalidad y vocación de permanencia.

- Se dirigen al pueblo para captar su apoyo y acumular fuerzas de manera que puedan ejercer el poder del Estado. En este mismo sentido son canal de participación del pueblo en el poder.

- Trabajan llevando a cabo operaciones de generación, agregación, transformación y articulación de intereses a fin de lograr mayor representatividad y acumulación de poder popular.

- Ejercitan una conducta democrática acorde con el sistema política predominante.

- Orientan la conciencia política con propuestas ideológicas y programáticas.

- Participan en elecciones y todo tipo de votaciones, como medios eficientes de logro de poder y representación formal dentro del Estado.

En el Perú estas organizaciones no funcionan desde hace muchos años como el canal de participación de los ciudadanos en el poder y como centro aglutinador de intereses de la población. El sistema político peruano está conformado por numerosos grupos integrados por pocos ciudadanos, que mayoritariamente no ejercen la democracia interna, que no logran formular posiciones de largo plazo para el país y que no cuentan con credibilidad frente a la población. Muchas veces los partidos políticos han girado más alrededor de los intereses de sus dirigentes que en torno a los intereses de la población a la que debían representar. En la práctica, los partidos políticos no han contribuido como otras organizaciones de la sociedad civil. Por el contrario han tendido a fragmentarse, razón por la cual existen varias 
agrupaciones políticas que no son mayormente disímiles entre sí en cuanto a postulados generales, pero que difícilmente pueden lograr alianzas y acuerdos duraderos. Estos problemas son similares en todos los partidos políticos, sin distinción de ideología o ubicación en el espectro político. Ello hace pensar que existen fundamentos que incentivan ese tipo de comportamiento entre los líderes políticos, al margen de sus posiciones o características personales (Instituto Apoyo 2000).

\subsubsection{Crisis de los partidos políticos}

Enrique Chirinos (1997:72-74) sostiene que en la Constitución de 1979, se dedicaban cuatro artículos a los partidos. En la Constitución de 1993, sólo se les dedica uno. La reducción en la presencia constitucional de los partidos no es casual sino sintomática. Delata la crisis que viven los partidos precisamente en la coyuntura de discutirse y aprobarse el nuevo texto constitucional ${ }^{34}$.

La crisis de los partidos políticos en el Perú es un fenómeno estructural, consecuencia de un proceso que se ha agudizado con el paso del tiempo y que tiene que ver con muchos factores como:

- La constante irrupción en la vida política de nuestro país con gobiernos autoritarios que obstaculizan el accionar de los partidos o la debilitan por excluirlos de la escena y del rol protagónico.
- La gran concentración de poder que tiene la Presidencia de la República, tanto por insuficiencia de la división de poderes como por el centralismo prevaleciente en el país.

- El diseño del sistema electoral establecido en la Constitución, que combina el distrito nacional único con la simultaneidad entre la elección presidencial y la parlamentaria. Según este enfoque, las reglas electorales básicas no establecen los incentivos para que los políticos sirvan a sus electores y se unan para fortalecer a las instituciones, sino que promueven la fragmentación de las agrupaciones, el personalismo de sus líderes y un ambiente poco propicio para la cooperación constructiva. Los líderes que quiebran partidos o los que insisten en candidaturas pequeñas, con lo que evitan alianzas, lo hacen porque la ley les abre posibilidades de permanencia en el Congreso aún con ínfimas votaciones.

En la siguiente tabla, se sintetizan las propuestas interpretativas sobre el inicio de la crisis de los partidos, sobre la base de los planteamientos de los autores siguientes: Sinesio López, Martín Tanaka, Julio Cotler, Nicolás Lynch, Fernando Tuesta.

Tabla N.o 02: Inicio de la crisis de los partidos

\begin{tabular}{|c|c|c|c|c|}
\hline SINESIO LÓPEZ & $\begin{array}{l}\text { MAR- } \\
\text { TÍN } \\
\text { TA- } \\
\text { NAKA }\end{array}$ & JULIO COTLER & NICOLÁS LYNCH & $\begin{array}{c}\text { FERNANDO } \\
\text { TUESTA }\end{array}$ \\
\hline $\begin{array}{l}\text { 1980: "No se consolida el sistema } \\
\text { de partidos, la crisis de la forma } \\
\text { partidaria de representación, se } \\
\text { expresa en el desacoplamiento } \\
\text { de los partidos con respecto a la } \\
\text { sociedad y al Estado que comen- } \\
\text { zaron a cambiar desde comienzos } \\
\text { de los } 80 \text {, que aceleraron dichos } \\
\text { cambios en los } 90 \text { ". }\end{array}$ & $\begin{array}{l}1989- \\
90, \quad \mathrm{El} \\
\text { proceso } \\
\text { de elec- } \\
\text { ciones. }\end{array}$ & $\begin{array}{l}\text { 1) } 1800 \text {...para } \\
\text { adelante. El pro- } \\
\text { blema de construir } \\
\text { un Estado. 2) } \\
\text { No } \\
\text { consolidación de } \\
\text { partidos políticos, } \\
\text { para los que hubo } \\
\text { una oportunidad } \\
\text { en el } 80 .\end{array}$ & $\begin{array}{l}\text { 1980-92* } 1980 \text {, Contexto internacional. } \\
\text { 1) Caída del muro de Berlín. 2) Globali- } \\
\text { zación de relaciones humanas desde una } \\
\text { forma neoliberal. * 1930: Horizonte His- } \\
\text { tórico. En los países latinoamericanos con } \\
\text { oligarquías más tradicionales, los partidos } \\
\text { que surgen son más radicales y por con- } \\
\text { frontación a dichas oligarquías, éste es el } \\
\text { caso del Perú. }\end{array}$ & $\begin{array}{l}\text { Desde 1980: } \\
\text { Perú con } \\
\text { sistema pre- } \\
\text { sidencialista } \\
\text { de gobierno } \\
\text { y sistema de } \\
\text { partidos frag- } \\
\text { mentados. }\end{array}$ \\
\hline
\end{tabular}

Fuente: CONGRESO DE LA REPÚBLICA, Partidos politicos, camino a una Ley. Aportes y propuestas; Lima 2003.

34 El artículo $35^{\circ}$ de nuestra Constitución dispone que los ciudadanos pueden ejercer sus derechos individualmente o a través de organizaciones políticas como partidos, movimientos o alianzas, conforme a Ley. Tales organizaciones concurren a la formación y manifestación de la voluntad popular. Su inscripción en el registro correspondiente les concede personalidad jurídica.

La Ley establece normas orientadas a asegurar el funcionamiento democrático de los partidos políticos, y la transparencia en cuanto al origen de sus recursos económicos y el acceso gratuito a los medios de comunicación social de propiedad del Estado en forma proporcional al último resultado electoral general. 
Según estos analistas políticos, el fracaso de los partidos políticos favoreció el éxito de las llamadas agrupaciones independientes alrededor de un líder carismático. Al margen de su posición en el espectro político, generalmente estas agrupaciones son de corto plazo, las que se mantienen como tales sólo mientras el líder está en una posición de poder efectivo. Sin embargo, han tenido una mayor capacidad para convocar a profesionales y técnicos y han mostrado mayor flexibilidad y renovación que los partidos políticos.
Por lo que el debilitamiento de los partidos políticos es un fenómeno negativo. El país debe aspirar a tener partidos políticos que funcionen mucho mejor que en el pasado, partiendo de reconocer que dichos partidos funcionaron en el marco de un sistema de reglas electorales que no propiciaba un mejor desempeño de los mismos.

Las razones que explican la crisis partidaria se basan tanto en las propias organizaciones políticas como en factores exógenos. En ese sentido, la tabla siguiente permite obtener una visión comparada sobre las razones de la crisis partidaria ${ }^{35}$.

Tabla N.o 03: Razones de la crisis partidaria

\begin{tabular}{|c|c|c|c|c|c|}
\hline $\begin{array}{l}\text { SINESIO } \\
\text { LÓPEZ }\end{array}$ & $\begin{array}{l}\text { MARTÍN } \\
\text { TANAKA }\end{array}$ & $\begin{array}{c}\text { JULIO } \\
\text { COTLER }\end{array}$ & NICOLÁS LYNCH & $\begin{array}{c}\text { FERNANDO } \\
\text { TUESTA }\end{array}$ & HENRY PEASE \\
\hline $\begin{array}{l}\text { 1) Incapacidad } \\
\text { de los partidos } \\
\text { políticos para } \\
\text { enfrentar la } \\
\text { violencia y cri- } \\
\text { sis económica. } \\
\text { 2) Destruc- } \\
\text { ción de nexos } \\
\text { vinculantes } \\
\text { entre partidos } \\
\text { políticos, ciu- } \\
\text { dadanos y so- } \\
\text { ciedad civil. }\end{array}$ & $\begin{array}{l}\text { Dice: “... que } \\
\text { los partidos } \\
\text { políticos sí han } \\
\text { tenido un nivel } \\
\text { de eficiencia } \\
\text { y que la crisis } \\
\text { se da por: 1) } \\
\text { Cambio de ló- } \\
\text { gica electoral } \\
\text { movimientista } \\
\text { a lógica electo- } \\
\text { ral mediática. } \\
\text { 2) Agotamien- } \\
\text { to de la matriz } \\
\text { estado-céntri- } \\
\text { ca y cambio a } \\
\text { la matriz mer- } \\
\text { cado-céntrica. }\end{array}$ & $\begin{array}{l}\text { 1) Tipo de } \\
\text { liderazg o } \\
\text { personalista, } \\
\text { patrimonia- } \\
\text { lista. 2) Polí- } \\
\text { tica partidaria } \\
\text { movimientis- } \\
\text { ta: prácticas } \\
\text { totalizadoras } \\
\text { antagónicas y } \\
\text { exclusivistas. }\end{array}$ & $\begin{array}{l}\text { La crisis de los partidos está } \\
\text { inmersa en una crisis mayor } \\
\text { que tiene dos características a } \\
\text { nivel internacional: 1) La crisis } \\
\text { de la forma elitista de hacer } \\
\text { política. 2) El desencadena- } \\
\text { miento de la política (crisis } \\
\text { de representación), encuen- } \\
\text { tra la crisis de representación } \\
\text { política en la incapacidad de } \\
\text { respuesta de los partidos a los } \\
\text { problemas estructurales que se } \\
\text { les plantearon: Agudización } \\
\text { de la desigualdad social. Crisis } \\
\text { económica crónica. Violencia } \\
\text { terrorista. La recreación de los } \\
\text { partidos con una dinámica de } \\
\text { enfrentamiento los despres- } \\
\text { tigió, e hizo caer al régimen } \\
\text { democrático en la ineficiencia } \\
\text { y en los peores casos, en la } \\
\text { irresponsabilidad. }\end{array}$ & $\begin{array}{l}\text { Fragmenta- } \\
\text { ción parti- } \\
\text { daria. Pola- } \\
\text { rización. El } \\
\text { debilitamiento } \\
\text { de los parti- } \\
\text { dos. Mayor } \\
\text { fortalecimien- } \\
\text { to del poder } \\
\text { ejecutivo. }\end{array}$ & $\begin{array}{l}\text { Sistema de partidos en } \\
\text { crisis. Débilmente ins- } \\
\text { titucionalizado en la } \\
\text { década de los } 80 \text { y deci- } \\
\text { didamente en los } 90 \text {, hay } \\
\text { partidos, pero éstos ni } \\
\text { son centrales en la esce- } \\
\text { na política ni logran ser } \\
\text { un sistema aunque la in- } \\
\text { teracción mutua, defen- } \\
\text { siva básicamente, se haya } \\
\text { incrementado...". Está de } \\
\text { acuerdo con Cotler con } \\
\text { respecto a la idea que } \\
\text { los partidos han repre- } \\
\text { sentado sólo intereses } \\
\text { fragmentados que han } \\
\text { llevado a la confronta- } \\
\text { ción. Señala las limitacio- } \\
\text { nes para la organización } \\
\text { partidaria de } 12 \text { años de } \\
\text { dictadura y las conse- } \\
\text { cuencias de un discurso } \\
\text { antipartido. }\end{array}$ \\
\hline
\end{tabular}

Fuente: CONGRESO DE LA REPÚBLICA, Partidos políticos, camino a una Ley. Aportes y propuestas; Lima 2003.

En general, los autores citados consideran que el colapso partidario se manifiesta durante la década de los noventa a partir de la proliferación de los denominados grupos independientes, la consolidación del fujimorismo, la desconfianza ciudadana respec- to de la necesidad de partidos políticos y la irrupción de un sistema multipartidista, todo lo cual se ratificó en desempeños electorales cada vez menos auspiciosos para los partidos históricos. En la tabla siguiente, los autores antes citados, establecen su diagnóstico. 
Tabla N.o 04: Colapso de los partidos políticos

\begin{tabular}{|c|c|c|c|c|c|}
\hline $\begin{array}{l}\text { SINESIO } \\
\text { LÓPEZ }\end{array}$ & $\begin{array}{l}\text { MARTÍN } \\
\text { TANAKA }\end{array}$ & $\begin{array}{l}\text { JULIO } \\
\text { COTLER }\end{array}$ & $\begin{array}{c}\text { NICOLÁS } \\
\text { LYNCH }\end{array}$ & $\begin{array}{c}\text { FERNANDO } \\
\text { TUESTA }\end{array}$ & HENRY PEASE \\
\hline $\begin{array}{l}\text { 1989-90, cuan- } \\
\text { do los indepen- } \\
\text { dientes entran } \\
\text { al poder van } \\
\text { desplazando a } \\
\text { la clase política } \\
\text { en asumir car- } \\
\text { gos: Belmont. } \\
\text { Fujimori. }\end{array}$ & $\begin{array}{l}\text { Lo sitúa en } \\
\text { 1995: "Triunfo } \\
\text { electoral de Fu- } \\
\text { jimori. Por qué: } \\
\text { "A la oposición } \\
\text { le faltó fortaleza } \\
\text { para combatir el } \\
\text { golpe del 92". } \\
\text { Ninguno de los } \\
\text { partidos llegó al } \\
5 \% \text { requerido } \\
\text { por el JNE en } \\
\text { el } 95 .\end{array}$ & $\begin{array}{l}\text { Entre } 1987 \text { y } \\
1992 \text { se pier- } \\
\text { de la fe en los } \\
\text { partidos. Y en } \\
1990 \text { se hace } \\
\text { evidente la } \\
\text { desintegración } \\
\text { del sistema de } \\
\text { partidos que } \\
\text { había existido } \\
\text { hace una dé- } \\
\text { cada. }\end{array}$ & $\begin{array}{l}1992 ; \quad \ldots \\
\text { "d o c e n i o } \\
1980-1992 \ldots, \\
\text { período de } \\
\text { estudio... fi- } \\
\text { nal de un ciclo } \\
\text { partidario que } \\
\text { va de } 1930 \text { a } \\
1992 \text { y que } \\
\text { tiene en el do- } \\
\text { cenio que nos } \\
\text { ocupa su últi- } \\
\text { mo acto..." }\end{array}$ & $\begin{array}{l}\text { A partir de } 1993 \text { se acen- } \\
\text { tuó el sistema multipar- } \\
\text { tidarista con una lata } \\
\text { fragmentación partidaria, } \\
\text { asociada a la precariedad } \\
\text { de la democracia que } \\
\text { conduce al inmovilismo } \\
\text { del sistema presidencia- } \\
\text { lista, que no crea su pro- } \\
\text { pia mayoría y menoscaba } \\
\text { el sistema político convir- } \\
\text { tiéndolo en sumamente } \\
\text { frágil. }\end{array}$ & $\begin{array}{l}\text { Está de acuerdo con Ta- } \\
\text { naka, en que el colapso } \\
\text { se dio en el } 95 \text {, y no en el } \\
92 \text {, pero añade razones. El } \\
\text { gobierno no estaba de sa- } \\
\text { lida, había derrotado a la } \\
\text { hiperinflación y capturado } \\
\text { a Abimael Guzmán. La no } \\
\text { participación de los parti- } \\
\text { dos en las elecciones del } \\
92 \text { (APRA y AP). En el } 95 \\
\text { van cada uno por su cuenta } \\
\text { frente a un candidato pode- } \\
\text { roso. }\end{array}$ \\
\hline
\end{tabular}

Fuente: CONGRESO DE LA REPÚBLICA, Partidos políticos, camino a una Ley. Aportes y propuestas; Lima 2003.

Los independientes -también conocidos como outsiders- aparecen en nuestro país como consecuencia de la crisis generalizada de los partidos políticos. Estos llegaron a consolidarse electoralmente y se presentan ante el electorado no como políticos sino como técnicos; de ahí el término de independientes. Se caracterizan por no ser herederos de una tradición cívica, y por no tener experiencia en el manejo institucionalizado de los asuntos públicos, convocan a operadores y funcionarios técnicos ajenos a los asuntos públicos $^{36}$. $\mathrm{Al}$ respecto, tres de los analistas citados anteriormente, se pronuncian de la siguiente manera:

Tabla N.o 05: Independientes

\begin{tabular}{|c|c|c|}
\hline SINESIO LÓPEZ & MARTÍN TANAKA & JULIO CO'TLER \\
\hline $\begin{array}{l}\text { Los outsiders * No son herederos } \\
\text { de una tradición cívica. * Inexperien- } \\
\text { cia en el manejo institucionalizado } \\
\text { de los asuntos públicos. } * \text { Convocan } \\
\text { a operadores y funcionarios técni- } \\
\text { cos ajenos a los asuntos públicos. } * \\
\text { Rechazan nominación de políticos } \\
\text { y prefieren aparecer como técnicos. } \\
\text { * Establecen relación directa con } \\
\text { ciudadanos sin mediaciones organi- } \\
\text { zativas apelando a los medios. * De- } \\
\text { cisiones centralizadas en el ejecutivo. } \\
\text { * Coaliciones con poderes fácticos. }\end{array}$ & $\begin{array}{l}\text { Los outsiders * Adquieren } \\
\text { relevancia al fallar el centro } \\
\text { y los extremos del sistema de } \\
\text { partidos políticos consolidán- } \\
\text { dose una autonomización de } \\
\text { gran parte del electorado. } * \\
\text { Independientes y no políticos. }\end{array}$ & $\begin{array}{l}\text { Los outsiders } * \text { Actores ajenos y contrarios a la clase } \\
\text { política. * Representantes de los valores antipolíticos. } * \\
\text { Se desembarazan rápidamente de los compromisos que } \\
\text { contraen. } \\
* \text { Denuncian los vicios del orden político. * Prometen } \\
\text { resolver personalmente los agravios y las aspiraciones } \\
\text { de las masas frustradas y desamparadas. * Encuestas de } \\
\text { opinión y los medios de comunicación son sus bases } \\
\text { de legitimación y consolidación. * Dan lugar a sistemas } \\
\text { delegativos fundados en fórmulas y relaciones plebisci- } \\
\text { tarias. } * \text { Su recetario es neoliberal: "Reducir funciones } \\
\text { estatales y fomentar el mercado mediante decisiones tec- } \\
\text { nocráticas (Chile por ejemplo). El respaldo lo consiguen } \\
\text { por eficacia de sus medidas. }\end{array}$ \\
\hline
\end{tabular}

Fuente: CONGRESO DE LA REPÚBLICA, Partidos políticos, camino a una ley. Aportes y propuestas; Lima 2003.

\footnotetext{
36 Los partidos políticos necesitan realizar diversos ajustes y reformulaciones en sus prácticas, estructuras y vinculaciones con la sociedad. Es necesario que ejerzan sus funciones de mediación y representatividad.
} 


\subsubsection{El sistema electoral}

El sistema electoral es un área muy importante en la que se puede incorporar mecanismos para mejorar la representatividad del Congreso y fortalecer las organizaciones políticas.

Para algunos, en el Perú resulta más viable mantener un sistema presidencialista que intentar un cambio radical hacia un sistema parlamentario ${ }^{37}$.

La elección por distrito electoral múltiple no sólo fomenta una mayor vinculación entre congresistas y electores, sino que también favorece la consolidación de un menor número de agrupaciones políticas sobre la base de alianzas de los grupos dispersos.

En opinión de algunos, la renovación por partes del Congreso a mitad del período gubernamental permitiría introducir elementos de cambio y de continuidad entre los gobiernos, lo que favorecería una mayor estabilidad. En vez de esta renovación por partes, la Constitución prevé que sean las elecciones municipales las que se lleven a cabo en esa fecha, a partir del año 2003, lo que las politiza innecesariamente.

\subsubsection{Democracia, prensa libre y transpa- rencia}

Solimano et al. (2008: 75) sostienen que los países que cuentan con un régimen democrático tienen una probabilidad menor de desarrollar prácticas corruptas que en un régimen autoritario o semidemocrático, ya que la información es más ampliamente difundida entre los ciudadanos en una democracia.Sólo tener elecciones regulares para elegir autoridades puede ser insuficiente. En este sentido, son muy importantes también la calidad y la estabilidad de la democracia. Estudios empíricos muestran que para que la democracia desincentive la corrupción, el sistema democrático debe estar asentado por varias décadas en forma ininterrumpida. Por tal razón, países latinoamericanos, africanos, asiáticos y del este de Europa, que en los últimos cuarenta años tuvieron ciclos de democracia-autoritarismo, no califican en esta condición.

Para Stiglitz (2003:21-24), si se quiere que la democracia funcione, los ciudadanos tienen la obligación de comprender los retos más cruciales a que se enfrentan nuestras sociedades y el modo en que operan nuestros gobiernos. La democracia es algo más que la convocatoria periódica de elecciones: implica dar cauces para que se oigan todas las voces, así como verificar que exista un proceso de deliberación.

North concibe a los gobiernos democráti$\cos ^{38}$ como un paso hacia una mayor eficiencia política, ya que el gobierno democrático da un porcentaje cada vez mayor al acceso del pueblo al proceso de toma de decisiones políticas, elimina la capacidad caprichosa de un gobernante para confiscar riquezas ${ }^{39}$, y desarrolla un cumplimiento obligatorio con un poder judicial independiente de lo que resulta sin duda un avance hacia una mayor eficiencia política. Pero sería erróneo afirmar que el resultado son mercados políticos eficientes, ya que ello exigiría una competencia vigorosa, tal como se da en los mercados económicos eficientes.

37 Existen dos modelos básicos de gobierno democrático: el parlamentarismo y el presidencialismo. La diferencia fundamental es la forma de elección del gobierno. En el parlamentarismo el pueblo elige a los miembros del parlamento y éstos al gobierno. Se trata por tanto, de una elección indirecta. En cambio, en el presidencialismo el pueblo elige de manera directa o semi directa tanto a los miembros del Congreso como al jefe de gobierno.

38 Forma de gobierno, de organización del Estado, en el cual las decisiones colectivas son adoptadas por el pueblo mediante mecanismos de participación directa o indirecta que le confieren legitimidad al representante.

39 Adam Smith, en su obra "Investigación sobre la naturaleza y causas de la riqueza de las naciones", afirma que la riqueza como dice Hobbes, es poder. Pero la persona que adquiere o hereda una gran fortuna, no por eso adquiere necesariamente ni hereda poderío político, civil o militar. Su riqueza podrá ofrecerles los medios para adquirir todo eso, pero la mera posesión de aquella no le procura necesariamente esas ventajas. El poder que le atribuye directa e inmediatamente esa posesión es la facultad de comprar; una cierta facultad de disposición sobre todo el trabajo o sobre todo el producto de este, que se encuentra en el mercado. 
La Constitución Política debe crear y establecer un marco legal apropiado, para limitar los Poderes del Estado, la protección de los derechos de la persona y la igualdad ante la Ley.

El Poder Legislativo debe mostrar, manifestar o demostrar fundamentalmente autonomía, modernidad y capacidad de fiscalización. Se requiere de un sistema que garantice la celeridad en la dación de las Leyes y la calidad de las mismas.

El Poder Ejecutivo no debe centralizar o concentrar el poder indebidamente, es necesario una mayor democratización de las instituciones de nuestro país. El Ejecutivo no puede caer en tentaciones antidemocráticas ni populistas.

El Poder Judicial debe ser totalmente autónomo frente a los otros Poderes del Estado, también se necesita moralizar y despolitizar el sistema judicial.

Un país sin sistemas institucionales capaces de manejar adecuadamente los programas de desarrollo económico, difícilmente aseguran el crecimiento económico.

\section{COMPETENCIA POLÍTICAY ALTERNANCIA EN EL PODER}

La competencia política implica la actividad continuada y simultánea, pre y post electoral, de varios partidos o agrupaciones políticas. Existe sólo cuando en los procesos políticos y electorales participan dos o más partidos. Las instituciones hereditarias, dictatoriales, unipartidistas, autoritarias eliminan la competencia política.

La falta de competencia política se da cuando se carece de un sistema político (conjunto de organismos políticos) que promueva el Estado de Derecho.

El crecimiento a largo plazo requiere del desarrollo del Estado de Derecho. Los prin- cipios del Estado de Derecho son: supremacía de la Ley, igualdad ante la Ley, seguridad jurídica, supremacía de las personas, justicia independiente, rápida y eficaz (administración de justicia ordenada). Es importante señalar que el Estado de Derecho, los derechos políticos (elecciones democráticas) y las libertades civiles (medios de comunicación libres e independientes, libertad de reunión y libertad de expresión) están correlacionados negativamente con la corrupción.

Para Solimano et al. (2008:77), el principal objetivo de los políticos es, por vocación o necesidad, la obtención del poder $y$, una vez alcanzado, la preservación del mismo. El mercado político en democracia se expresa en elecciones y otros mecanismos que se supone premian o castigan el comportamiento de los líderes políticos y de los gobiernos según sus acciones y resultados. Así, el grado de competencia política y la alternancia en el poder son variables que pueden ser importantes para reducir (o aumentar) la corrupción. En efecto, las presunciones o evidencia de corrupción pueden afectar negativamente la imagen de los políticos o gobiernos que sean percibidos en actos de corrupción lo que, naturalmente, afectará el resultado de la competencia electoral. Así, las elecciones y el juicio ciudadano pueden incentivar un comportamiento limpio de los políticos y de los gobiernos, ya que posibles prácticas corruptas-percibidas o reales- si son conocidas por la ciudadanía, pueden hacer perder elecciones. En algunos casos, pueden desencadenar también la pérdida del poder por medio de protestas sociales.

En cuanto a los partidos políticos, es necesario democratizarlos. Es inconcebible e impracticable la democracia sin los partidos políticos. Para crecer económicamente debe existir estabilidad política; por lo que se requiere la democratización, renovación y modernización de los partidos políticos. 
Sin embargo, si los programas o planteamientos de la clase política no son correspondientes con las reformas económicas, sociales y con las expectativas de la población en general, los partidos políticos tienden a desaparecer o simplemente, se convierten en un grupo de personalidades o partido de "personas notables".

Son los Poderes del Estado los que determinan el funcionamiento económico, porque son ellos los que definen e imponen las reglas de juego económicas. Por esta razón, el objetivo fundamental de la política de desarrollo de un país debe consistir en la creación de un Estado que establezca e imponga derechos de propiedad eficientes.

\section{CONCLUSIONES}

1. Las instituciones estructuran los incentivos en el intercambio humano, reducen los costos de transacción, garantizan los derechos de propiedad y aseguran el cumplimiento de los contratos. Esta estructura de los incentivos crea una estructura productiva. La importancia de las instituciones en el desarrollo económico radica en que reducen la incertidumbre y el riesgo. En tal sentido, existe un amplio consenso en aceptar la importancia de las instituciones para explicar tanto el éxito como el fracaso de los países en su desarrollo. Sin embargo, el consenso es menor cuando se trata de decidir qué instituciones tienen más importancia y cuál es la forma concreta que deben adoptar. El "cómo" del desarrollo institucional sigue siendo un misterio.

2. Una de las causas fundamentales por las cuales, las instituciones son ineficaces es la falta de competencia política. Se carece de organismos políticos que promuevan el Estado de Derecho, en el cual los derechos políticos (elecciones democráticas) y las libertades civiles (medios de comunicación libres e independientes, libertad de reunión y libertad de expresión) están correlacionados negativamente con la corrupción. La debilidad del sistema político hace difícil predecir la identidad de los gobiernos futuros, lo cual hará que los inversionistas trasladen sus recursos a medios institucionales más predecibles o más seguros. Es necesario que el Estado cumpla su rol y haga prevalecer fundamentalmente, la supremacía de la Ley, el respeto por la Ley y la seguridad jurídica. La piratería existe porque el riesgo de delinquir es relativamente bajo comparado con el beneficio obtenido. Si la matriz institucional recompensa la piratería, entonces aparecerán organizaciones piratas.

3. Cualquier reforma que tenga como finalidad lograr un desarrollo económico sustentable, debe primero establecer un marco institucional que genere estabilidad política, económica y social. Un Estado que ejerce su poder de forma discrecional desincentiva la calidad y eficiencia inversiones y el gasto social, considerados esenciales para alcanzar un desarrollo económico sostenido en el tiempo. Son los Poderes del Estado (Ejecutivo, Legislativo y Judicial) los que determinan el funcionamiento económico, porque ellos definen e imponen reglas de juego de la sociedad. Por esta razón, el objetivo fundamental del desarrollo económico de un país debe consistir en la creación de un Estado que establezca e imponga derechos de propiedad eficientes.

4. Una diferencia fundamental entre un país en vías de desarrollo y otro desarrollado, es que los derechos de propiedad 
en el caso del primero, se encuentran mal definidos o se caracterizan por ser poco efectivos. Por lo tanto, no solamente el marco institucional tendrá altos costos de transacción, sino que la inseguridad en los derechos de propiedad dará como resultado la utilización de tecnologías que emplean poco capital fijo y que no significan acuerdo a largo plazo.

5. La debilidad institucional o la inexistencia de reglas de juego claras y su implicancia en el crecimiento económico, puede conllevar a crisis económicas severas, ya que la inversión de las empresas se vería considerablemente afectada en la medida que los derechos de propiedad legal sean inciertos o inconstantes, las leyes no se respeten o exista inseguridad jurídica, etc.Por ello el cambio institucional es fundamental para el crecimiento y desarrollo económico. Si cambian las reglas de juego en el nuevo sistema de economía de mercado, es necesario que el marco institucional de esas reglas de juego cambien y se adecuen al nuevo funcionamiento de la economía y le permita generar la confianza y eficiencia operativa, reduciendo los costos de transacción, garantizando los derechos de propiedad y asegurando el cumplimiento de los contratos. Si bien es cierto las instituciones determinan el desempeño económico de las economías, se debe tener muy en cuenta que el mejor diseño institucional es el que mejor funciona; por lo tanto, no hay ninguna solución universal que se pueda aplicar indiscriminadamente a cualquier caso; $y$, aun en el caso de una solución ideal, no hay forma de imponer una solución institucional sin considerar las fuerzas políticas y los recursos disponibles, pues la reforma institucional afecta la distribución de poder $\mathrm{y}$, por ende, implica ganadores $\mathrm{y}$ perdedores.

6. El desempeño económico es un resultado de la interacción entre organizaciones políticas, económicas, sociales y educativas con las instituciones existentes. Sin embargo, el sistema político conduce a la selección de instituciones formales, éstas determinan la selección del tipo de organización económica y el desempeño económico. Los países que logren establecer un marco institucional bien definido (reglas de juego claras) que estructure los incentivos en el intercambio humano, reduzca los costos de transacción, garantice los derechos de propiedad y asegure el cumplimiento de los contratos, fomente el nivel de confianza mutua entre sus miembros, garantice la competencia y obligue al gobierno a respetar sus acuerdos y políticas, tenderán a ser más exitosos en su desempeño económico.

7. En el caso de los países de latinoamérica, el marco conceptual de las instituciones nos permite comprender la situación de subdesarrollo, a partir del análisis de la calidad de las instituciones para incentivar la inversión productiva y la eficiencia económica en general. Se necesita reestructurar las reglas del juego y crear instituciones que produzcan crecimiento. Si se cuenta con estructuras sólidas de derechos de propiedad, sistemas legales que posibiliten las transacciones y eliminen los altos costos de obtener la información y otras instituciones, se producirá el resultado anhelado del crecimiento económico. Para conseguir o crear estas instituciones, primero hay que establecer un conjunto de reglas informales que complementen y apoyen las instituciones formales. Segundo debe construir- 
se un sistema político sólido que sepa cómo poner en marcha las reglas del juego y hacer que la población las cumpla.

8. Las economías como la nuestra, no cuentan con sistemas institucionales eficaces. El Estado peruano se caracteriza por ser un Estado débil (los esfuerzos realizados hasta ahora no son los más eficaces) y como es de entender, la debilidad institucional es un obstáculo para cualquier intento de crecimiento económico sostenido. Se requiere de reformas institucionales, especialmente de la existencia de reglas de juego que aseguren los derechos de propiedad legal y de mecanismos legales que los protejan. Asimismo, hace falta que se garantice el imperio de la Ley, un marco legal que limite constitucionalmente el poder de los gobiernos de turno, la reforma de la administración de justicia (sistema judicial independiente, rápido y eficaz), la reforma de la capacidad de fiscalización del Poder Legislativo y la reforma educativa (las instituciones educativas son los caminos de bienestar y libertades personales). Todo esto requiere del gobierno; sin embargo, es importante tener en cuenta que un gobierno muy opresivo no es la única razón que imposibilita los mercados; generalmente, el problema radica en un gobierno demasiado débil.

\section{BIBLIOGRAFÍA}

1. AYALA, José Instituciones y Economía. México. Editorial Fondo de Cultura Económica.

2. BOYD R. y P.J. RICHERSON Culture and the Evolutionary Process. Chicago. University of Chicago Press.

3. CHIRINOS, Enrique 1997 Constitución de 1993. Lectura y comentario.
Lima. Cuarta edición, Editor Antonella Chirinos Montalbetti.

4. CONSTITUCIÓN POLÍTICA DEL PERÚ 1993.

5. CONGRESO DE LA REPÚBLICA 2003 Partidos políticos, camino a una ley. Aportes y propuestas. Lima.

6. DE SOTO, Hernando 2000El Misterio del Capital. Lima. Editora El Comercio S.A.

7. FARINA, Juan M. 1997 Contratos Comerciales Modernos. Buenos Aires. Segunda Edición, Editorial Astrea.

8. FRANK, Robert 1992 Microeconomía y Conducta. España. Editorial McGrawHill.

9. INSTITUTO APOYO 2000 Reforma Política. Modernización del Congreso. Primera Edición.

10. GARCÍA, Víctor 2008 Teoría del Estado y Derecho Constitucional. Lima. Palestra Editores.

11. HOLMES S. Passion and Constraints. On the Theory of Liberal Democracy. Chicago. The University of Chicago Press.

12. JOSEPH, Jaime 2005 La ciudad, la crisis y las salidas: Democracia y desarrollo en espacios urbanos meso. Lima. Fondo Editorial de la Facultad de Ciencias Sociales UNMSM.

13. KRUGMAN, Paul 2009 De Vuelta a la Economía de la Gran Depresión y la Crisis del 2008. Colombia. Grupo Editorial Norma.

14. NORTH, Douglass Instituciones, Cambio Institucional y Desempeño Económico. México. Primera edición en español. Editorial Fondo de Cultura Económica. 2007 Para entender el proceso de cambio económico. Colombia. Editorial Norma S.A. 
15. PÉREZ, Nicolás 1984 Tratado de Derecho Político. Madrid. Editorial Civitas.

16. ROEMER, Andrés 1994 Introducción al análisis económico del derecho. México. Fondo de Cultura Económica.

17. RUBIO, Marcial 1997 Ley de Partidos Políticos. Las Reglas que nadie quiso aprobar. Lima. Pontifica Universidad Católica del Perú.

18. SARDÓN, José Luis Estado, Política y Gobierno. Lima. Universidad del Pacífico.

19. SOLIMANO, Andrés; TANZI Vito y Felipe DEL SOLAR 2008 Las Termitas del Estado. Chile. Editorial Fondo de Cultura Económica.
20. SUÁREZ, Andrés S. Diccionario de Economía y Administración. España. Editorial McGraw-Hill/Interamericana de España S.A.

21. SUGDEN, Robert The Economics of Rights, Cooperation, and Welfare; Blackwell, Oxford.

22. STIGLITZ, Joseph E. Los felices 90. La semilla de la destrucción. Argentina. Santillana Ediciones Generales.

23. WIESE, Carol 2003 Reinventando el Estado: estrategia económica y cambio institucional en el Perú. Lima. Universidad del Pacífico. 